\title{
Direct Comparison of Odor Responses of Homologous Glomeruli in the Medial and Lateral Maps of the Mouse Olfactory Bulb
}

\author{
Tokiharu Sato, ${ }^{1,2}{ }^{\circledR}$ Ryota Homma, ${ }^{1}$ and ${ }^{\circledR}$ Shin Nagayama ${ }^{1}$ \\ https://doi.org/10.1523/ENEURO.0449-19.2020 \\ ${ }^{1}$ Department of Neurobiology and Anatomy, McGovern Medical School at the University of Texas Health Science \\ Center at Houston, Houston, TX 77030 and ${ }^{2}$ Department of System Pathology for Neurological Disorders, Brain \\ Research Institute, Niigata University, Niigata 951-8585, Japan
}

\begin{abstract}
Olfactory sensory neurons (OSNs) expressing same-type odorant receptors typically project to a pair of glomeruli in the medial and lateral sides of the olfactory bulbs (OBs) in rodents. This multiple glomerular representation of homologous inputs is considered to have more important functional roles for odor information processing than the redundant backup system. However, a consensus idea is lacking and this hinders interpretation of the phenomenon. In addition, the shared and unique odorant response properties of the homologous glomeruli remain unclear because the majority of medial glomeruli are hidden in the septal OB, and thus it is difficult to directly compare them. OSNs, which express trace amine-associated odorant receptors (TAARs), were recently identified that project to a pair of glomeruli uniquely located in the dorsal OB. In this study, we measured the odorant-induced calcium responses of homologous pairs of TAAR glomeruli simultaneously in anesthetized mice and directly compared their response patterns. We found that they exhibited similar temporal response patterns and could not find differences in onset latency, rise time, decay time, or response amplitude. However, the medial glomeruli had significantly larger respiration-locked calcium fluctuations than the lateral glomeruli. This trend was observed with/without odorant stimulation in postsynaptic neurons of GABAergic, dopaminergic, and mitral/tufted cells, but not in presynaptic olfactory sensory axon terminals. This indicates that, at least in these TAAR glomeruli, the medial rather than the lateral OB map enhances the respiration-locked rhythm and transfers this information to higher brain centers.
\end{abstract}

Key words: calcium imaging; glomerulus; map; mouse; olfactory bulb; respiration

\section{Significance Statement}

This study directly compared the odor-evoked responses in paired homologous glomeruli in medial and lateral maps in the mouse dorsal olfactory bulb (OB) using the in vivo calcium imaging technique, which revealed that the response amplitude, onset latency, rising time, and decay time were not significantly different between medial and lateral homologous glomeruli. However, postsynaptic but not presynaptic neuronal activity in medial glomeruli had stronger respiratory-locked calcium fluctuations than lateral glomeruli. These differences were also observed in the resting condition without odor stimulation. The results suggest that the medial map neurons enhance respiratory-linked odor representation and transmit it to higher brain centers. 


\section{Introduction}

Parallel processing of multiple streams of information improves the speed of processing and provides redundancy for fail-safe operations. Biological parallel streams of information in the brain are not typically identical neuronal circuits but have unique as well as common properties (Kandel et al., 2013). How the brain organizes the distinct processing streams and combines them is not well understood.

Odor information is represented as spatial/temporal glomerular activity patterns on the surfaces of the olfactory bulbs (OBs). In rodents, olfactory sensory neurons (OSNs) expressing the same types of odorant receptors, among $\sim 1000$ repertoires (Buck, 1996), convert chemical signals into electrical signals in a respiratory rhythm and project to approximately two glomeruli in the OB: one on the medioventral side and the other on the dorsolateral side. The axons of these OSN projections traverse the medial/septal and lateral surfaces of the OBs, respectively. Because the two homologous glomeruli are arranged symmetrically in the OB, odor information is represented and processed in two mirror maps (Mombaerts et al., 1996; Nagao et al., 2000, 2002; Zapiec and Mombaerts, 2015). The paired glomeruli are connected via axon collaterals of tufted cells in a point-to-point manner (Belluscio et al., 2002; Lodovichi et al., 2003; Marks et al., 2006). Although the anatomic arrangements of the two maps have been studied, less is known about the functional connections between them (Zhou and Belluscio, 2008, 2012). One pivotal idea is that the complex structure of the olfactory epithelium (OE) affects the sensitivity and timing of odorant responses of OSNs such that a delayed odorant response in one of the maps occurs with low odor concentrations (Kimbell et al., 1997; Schoenfeld and Cleland, 2006; Zhao et al., 2006; Zhou and Belluscio, 2012). The similarity in the spatiotemporal patterns representing odor information between these glomeruli remains unknown, partly because of the inaccessibility of the medial map, but is essential to understand the features that are common and uncommon between the two streams.

Trace amine-associated receptors (TAARs) were recently recognized as a second gene family of odorant receptors (Liberles and Buck, 2006). Pairs of OSNs expressing TAARs project to glomeruli in the mediodorsal OB (Ferrero et al., 2011; Pacifico et al., 2012; Dewan et al., 2013; Zhang et al., 2013; Liberles, 2015), which can frequently be observed simultaneously. Moreover, these two glomeruli are functionally identifiable because of their highly selective responses to the specific odorant at a low

This work is supported by the National Institutes of Health Grant R01DC013802 (to S.N.).

Acknowledgments: We thank Dr. Dewan for discussions of odorant response properties and the location of TAAR glomeruli.

Correspondence should be addressed to Shin Nagayama at shin.nagayama@ uth.tmc.edu.

https://doi.org/10.1523/ENEURO.0449-19.2020

Copyright (C) 2020 Sato et al.

This is an open-access article distributed under the terms of the Creative Commons Attribution 4.0 International license, which permits unrestricted use, distribution and reproduction in any medium provided that the original work is properly attributed. concentration (Zhang et al., 2013). In the present study, we measured simultaneous odorant responses of these homologous glomerular pairs and compared the response properties between medial and lateral maps. These glomeruli exhibited similar activity patterns of response onset latency, rise and decay times, and amplitudes. However, the medial glomeruli showed significantly larger respiration-locked fluctuations than the lateral glomeruli. The difference was observed in postsynaptic neuronal responses but not presynaptic terminal activity, suggesting that despite similar inputs, the medial map neurons and/or circuits enhance the respiration-locked activity for further odor information processing.

\section{Materials and Methods}

All procedures were performed on mice of either sex in accordance with National Institutes of Health guidelines and approved by the Animal Welfare Committee at the University of Texas Health Science Center at Houston.

\section{Animals}

Cre recombinase (Cre)-inducible GCaMP3-expressing mice (Ai38; \#014538; RRID:IMSR_JAX:014538; Zariwala et al., 2012) were used for the expression of the calcium indicator in target neurons. This mouse line was crossed with the following Cre-driver mouse lines: OMP-Cre (for OSNs, \#006668; RRID:IMSR_JAX:006668; Li et al., 2004), Gad2Cre (for GABAergic neurons, \#010802; RRID:IMSR_JAX: 010802; Taniguchi et al., 2011), DAT-Cre (for dopaminergic neurons, \#006660; RRID:IMSR_JAX:006660; Bäckman et al., 2006), and Pcdh21-Cre (for mitral/tufted cells, $\# \mathrm{O}_{2}, 189$; RRID:IMSR_RBRC02189; Nagai et al., 2005). Ai38, OMPCre, Gad2-Cre, and DAT-Cre mouse lines were purchased from The Jackson Laboratory. The Pcdh21-Cre mouse line was obtained from the RIKEN BioResource Research Center. All animals used in the experiments were aged between 8 and 16 weeks.

\section{Histology}

Mice were deeply anesthetized and fixed by transcardial perfusion with $4 \%$ paraformaldehyde (PFA) in $0.1 \mathrm{M}$ phosphate buffer (PB; pH 7.4). Then, whole brains were dissected out and postfixed in 4\% PFA/0.1 M PB overnight. The samples were cryoprotected in 30\% sucrose (wt/vol) in PBS (pH 7.4) and embedded in optimal cutting temperature compound (Fisher HealthCare). Olfactory tissue sections $30 \mu \mathrm{m}$ thick were cut on a cryostat, washed with PBS, and mounted with Fluoroshield mounting medium (F6057; Sigma-Aldrich). Images were captured on an Olympus FluoView FV1000 laser scanning confocal microscope using a $20 \times / 0.75 \mathrm{NA}$ lens objective (UPLSAPO 20X; Olympus).

\section{Odorant stimulation}

Isopentylamine (IPA; \#126810; Sigma-Aldrich) and phenylethylamine (PEA; \#128945; Sigma-Aldrich) were diluted in mineral oil (M3516; Sigma-Aldrich) to $0.1 \%$ and $0.01 \%$ in glass vials. The odorants were vaporized using nitrogen, mixed with filtered air to final concentrations of 
$0.02 \%$ and $0.002 \%$ with $0.5 \mathrm{l} / \mathrm{min}$ air flow rate, and then delivered to mouse nostrils using a custom-made olfactometer (Kikuta et al., 2013). The odorants were presented for $2 \mathrm{~s}$ with an interstimulus interval of $>60 \mathrm{~s}$ to avoid sensory adaptation.

\section{In vivo optical imaging}

GCaMP-expressing mice were anesthetized with urethane (1.2 $\mathrm{g} / \mathrm{kg}$ of body weight, i.p.). The depth of anesthesia was monitored by toe pinches throughout the experiment. Body temperature was kept between $36.0^{\circ} \mathrm{C}$ and $37.0^{\circ} \mathrm{C}$ with a heating pad. The skull over the OBs was carefully thinned with a dental drill and covered with $1.2 \%$ agarose dissolved in saline and with a 4-6 $\mathrm{mm} \times$

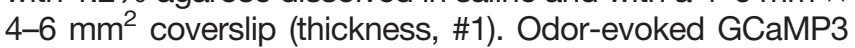
signals were recorded through a $5 \times$ lens objective (Fluar $5 \times / 0.25$; Zeiss) on a microscope (SliceScope; Scientifica) equipped with a high-speed charge-coupled-device camera (NeuroCCD-SM256; RedShirtlmaging) at $125 \mathrm{~Hz}(128 \times$ 128 pixels) for $12 \mathrm{~s}$, which included a 4-s prestimulus period and a 2-s odor presentation period. Excitation light was provided using a 470-nm light-emitting diode module (M470L2; Thorlabs). A standard green fluorescent protein filter set (BrightLine GFP-4050A-OMFZERO; Semrock) was used to detect the GCaMP3 signal. Chest movement of the animals was monitored to measure the respiratory rhythm during the optical imaging period.

\section{Dil labeling of OSN axons}

After calcium imaging, the skull over the dorsal OBs was removed. Then, small Dil (1,1'-dioctadecyl-3,3,3'3'tetramethylindocarbocyanine perchlorate) crystals were attached to the tip of glass capillaries (tip diameter, $\sim 5 \mu \mathrm{m}$ ) and embedded into the area of IPA-responsive glomeruli. The positions of blood vessels relative to homologous pairs of glomeruli were used as landmarks for Dil implantation. The mice remained anesthetized for 9$10 \mathrm{~h}$ after Dil implantation and then were fixed by transcardial perfusion with 4\% PFA/0.1 M PB. Whole brains were removed and incubated in PBS at room temperature until observation. Low-magnification images were captured by a charge-coupled-device camera (NeuroCCDSM256 or SensiCam; PCO) using a $5 \times$ lens objective (Fluar $5 \times / 0.25$, Zeiss) with a light-emitting diode module (MCWHL2-C1; Thorlabs) and a standard Сy3 cube (BrightLine Cy3-4040C-OMF-ZERO; Semrock). For highmagnification views of OSN axons, images were acquired with a two-photon microscope (Prairie Ultima), using a 20x water immersion lens objective (UMPLFLH 20XW; Olympus), with a $5-\mu \mathrm{m}$ inter-z-slice interval and $512 \times 512$-pixel resolution. Dil was excited at $920 \mathrm{~nm}$ (Ti: sapphire laser, MaiTai HP DS; Spectra-Physics), and Dil fluorescence was detected with an emission filter cube (575-nm dichroic mirror and 607/45-nm barrier filters).

\section{Data analysis for wide-field calcium imaging data}

Odor-evoked response maps were generated using Fiji/ ImageJ (RRID:SCR_002285; Schindelin et al., 2012) with custom-written scripts. Spatially filtered $(3 \times 3$ mean filter) prestimulation-period images (4s) were averaged and used as a baseline $\left(F_{0}\right)$. Images averaged $3 \mathrm{~s}$ after the onset of the 1-s odor stimulation were used as the response image $(F)$. Then, $F$ was subtracted from $F_{0}$ to obtain the difference $(\Delta \mathrm{F}) . \Delta \mathrm{F}$ values were divided by $\mathrm{F}_{0}$ to obtain the ratio image $\left(\Delta F / F_{0}\right)$. Spatial filters $(3 \times 3$ mean filter) were also applied to the ratio images. All negative values were set to zero in the images. Regions of interest corresponding to glomeruli were manually set (four to eight pixels centered on each glomerulus).

The time courses of calcium signals (Fig. $2 B$ ) were calculated using MATLAB (MathWorks; RRID:SCR_001622) with custom-written scripts. $\Delta F / F_{0}$ values were calculated using the same procedure described above but with a temporal filter (three frames average, $24 \mathrm{~ms}$ ) rather than a spatial filter applied to the $\Delta F / F_{0}$ values.

Onset latency, rise time, decay time, and peak amplitude were computed with custom MATLAB scripts. First, the baseline values $\left(\triangle \mathrm{F} / \mathrm{F}_{0}\right)$ were determined as the mean values over the baseline period, which was defined as a duration of $1 \mathrm{~s}$ during the prestimulation period. Then, the noise level in each trial was defined as the minimum standard deviation among eight 0.5 -s blocks in the 4-s prestimulation period. The onset latency was determined as the first time point at which all data points in the subsequent $80 \mathrm{~ms}$ exceeded the threshold (2.5 times the noise level). The onset latency was measured as the time elapsed from the first inhalation after the onset of odor presentation. The rise time was defined as the duration the calcium signals increased from $20 \%$ to $80 \%$ of peak amplitude. Time points for when the calcium signals reached $20 \%$ and $80 \%$ of the peak amplitude were set as the earliest time point after which half of the data points in the subsequent $80 \mathrm{~ms}$ exceeded these criteria. The decay time was defined as the duration the calcium signal decreased from $100 \%$ to $50 \%$ of the peak amplitude. Time points for when the calcium signals reached $100 \%$ and $50 \%$ of peak amplitude were set as the earliest time point after which half of data points in the subsequent $80 \mathrm{~ms}$ dropped below these criteria. The peak amplitude was measured as the maximum value using the $80-\mathrm{ms}$ time window moving average, which reflects an average of nine sequential data points, after stimulation onset.

To analyze fluctuations in the calcium fluorescence, a power spectral analysis based on Fourier transform was used. First, $\Delta \mathrm{F} / \mathrm{F}_{0}$ values were preprocessed with a $40-\mathrm{ms}$ box filter and divided into two periods, corresponding to prestimulation ( $2 \mathrm{~s}$ before onset of odor stimulation) and odor stimulation (4 $\mathrm{s}$ after onset of odor stimulation). Then, a power spectrum was computed by using Fast Fourier transform with 2048 points [using a built-in function of MATLAB (fft.m)] in each period. Because we used a $125-\mathrm{Hz}$ sampling frequency, the frequency resolution is $0.061 \mathrm{~Hz}$. The peak power in each period was determined as the maximum value between 2 and $4 \mathrm{~Hz}$. The background baseline was defined as the mean value of the power spectrum between 6 and $9 \mathrm{~Hz}$ and was subtracted from the spectrum. 
A Cre driver mice $x$ GCaMP3 reporter mice (Ai38)
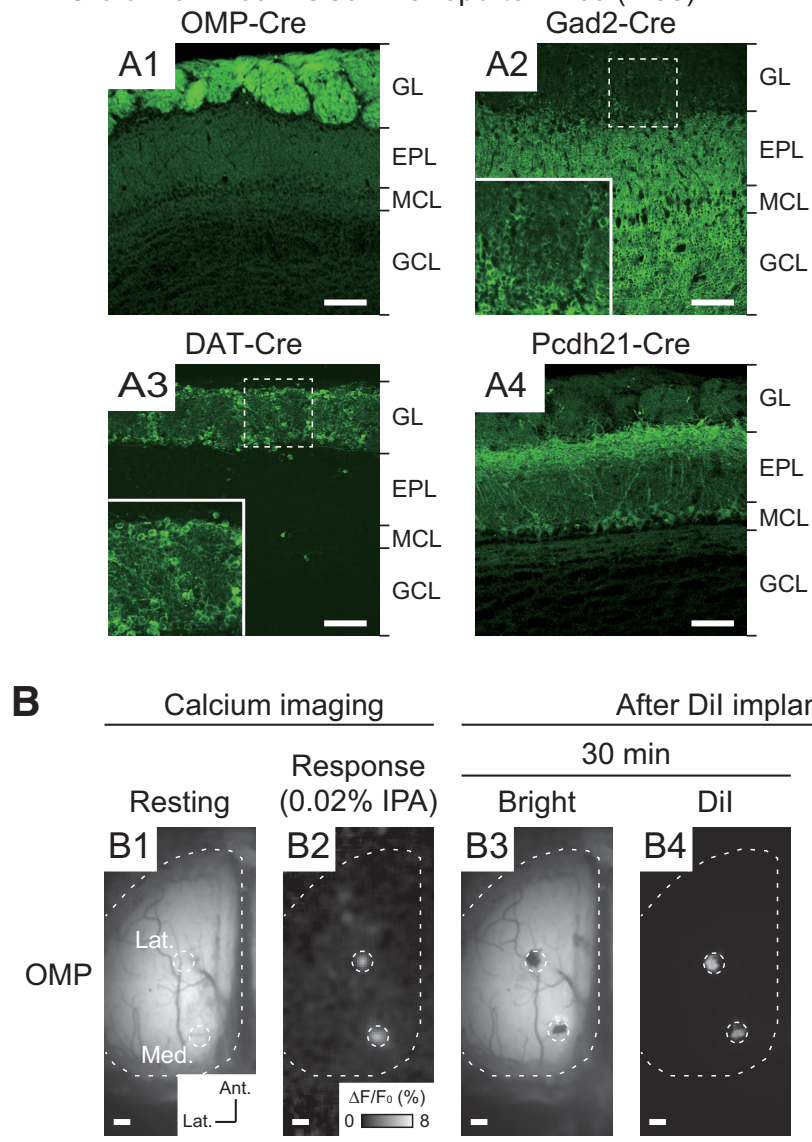

After Dil implantation

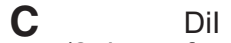

D

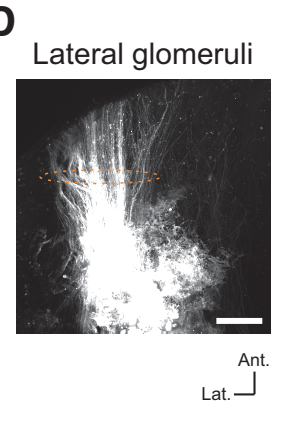

E
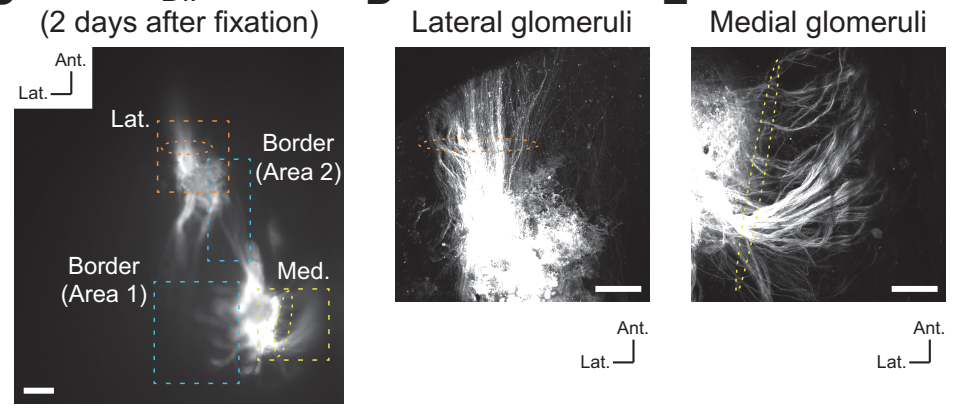

F Border between lateral and medial maps Area 1

$$
\text { Area } 2
$$
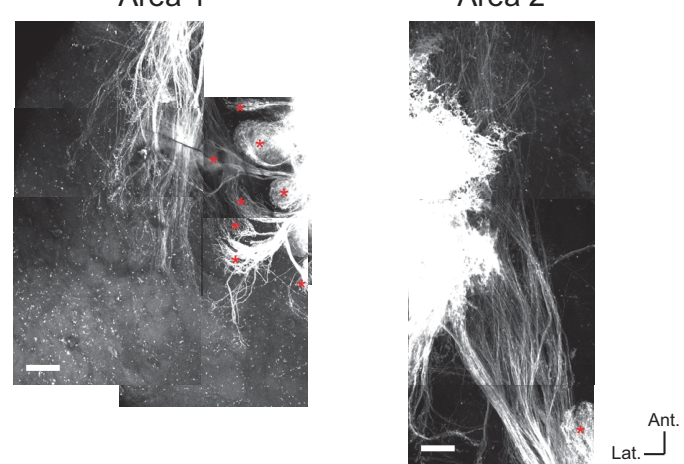

Figure 1. Cell-type-specific expression of GCaMP3 in OBs and distinct OSN axon trajectories in IPA-responsive glomeruli. $\boldsymbol{A 1 - A 4}$, Confocal images of OBs in Cre-dependent GCaMP3 reporter mice crossed with OMP-Cre (A1), Gad2-Cre (A2), DAT-Cre (A3), and 
continued

Pcdh21-Cre (A4) mice. Magnified views of the dashed squares are shown in the insets in $\boldsymbol{A 2}, \boldsymbol{A 3}$. GL, EPL, MCL, and GCL indicate GL, external plexiform layer, MCL, and GCL, respectively. B, Process for the Dil labeling of OSN axons. B1, Resting fluorescence of GCaMP3 in the dorsal OB of OMP-Cre mouse. B2, IPA (0.02\%)-responsive homologous glomeruli were observed by calcium imaging [color scale indicates $\Delta F / F_{0}(\%)$ of GCaMP3 signal]. B3, Brightfield image after Dil implantation. B4, Dil fluorescence 30 min after Dil implantation. B5, Dil fluorescence $8 \mathrm{~h}$ after Dil implantation. The locations of IPA-responsive glomeruli are indicated by the white dotted circles. $\boldsymbol{C}$, Two-photon microscopy image of Dil-labeled glomeruli and OSN axons $2 \mathrm{~d}$ after Dil implantation. $\boldsymbol{D}$, Magnified image of area denoted by orange dotted square in $\boldsymbol{C}$ associated with lateral glomerulus. $\boldsymbol{E}$, Magnified image of area denoted by yellow dotted square in $\mathbf{C}$ associated with medial glomerulus. Two-photon microscopy images of OSN axons that transverse the lateral and medial surface of $\mathrm{OB}$; orange and yellow dotted ellipses (in $\boldsymbol{C}-\boldsymbol{E}$ ) represent major axonal projections from lateral and medial glomeruli. $\boldsymbol{F}$, Two-photon microscopy images of areas of lateral/medial border denoted by blue dotted square in $\boldsymbol{C}$. Red asterisks indicate axon termination in several glomeruli in which the labeled OSNs probably passed through the surface of the Dil-implanted glomeruli. Some minor axons which did not show clear axon terminations in a glomerulus were observed in area 2 in this case. Ant., anterior. Lat., lateral. Scale bars: $100 \mu \mathrm{m}(\boldsymbol{A}), 200 \mu \mathrm{m}(\boldsymbol{B}, \boldsymbol{C}), 50 \mu \mathrm{m}(\boldsymbol{D}, \boldsymbol{E})$, and $100 \mu \mathrm{m}(\boldsymbol{F})$.

\section{Experimental design and statistical analyses}

Experiments were designed to simultaneously record odor-evoked responses from homologous glomerular pairs and to compare the response properties between the medial and lateral maps as described above.

Statistical analyses were performed using Microsoft Excel 2013. All statistical significance was determined by a twotailed paired Student's $t$ test; $p<0.05$ was considered statistically significant. Data are presented as scatter and boxwhisker plots of pooled datasets for a given odorant and concentration from OMP-Cre (279 trials in 0.02\% PEA, 194 trials in $0.002 \%$ PEA, 297 trials in $0.02 \%$ IPA, and 185 trials in $0.002 \%$ IPA; $n=10$ ), Gad2-Cre (106 trials in $0.02 \%$ PEA, 84 trials in $0.002 \%$ PEA, 119 trials in $0.02 \%$ IPA, and 62 trials in $0.002 \%$ IPA; $n=6$ ), DAT-Cre (216 trials in $0.02 \%$ PEA, 118 trials in $0.002 \%$ PEA, 184 trials in $0.02 \%$ IPA, and 123 trials in $0.002 \%$ IPA; $n=6$ ), and Pcdh21-Cre (199 trials in $0.02 \%$ PEA, 130 trials in $0.002 \%$ PEA, 241 trials in $0.02 \%$ IPA, and 176 trials in $0.002 \%$ IPA; $n=6$ ) mice. In scatter plots, individual dots show data points from single trials. In box-whisker plots, horizontal red lines and boxes indicate the medians and quartiles, respectively. The whiskers go from each quartile to the minimum or maximum. All statistical data (sample size, 95\% confidence interval, mean, standard deviation, and $p$ values) are listed in Table 2.

\section{Results}

\section{Expression patterns of GCaMP3 in OBs from Cre mouse driver lines}

We recorded odor-evoked neuronal activity in the OBs of mice from multiple transgenic mouse lines. To express the genetically encoded calcium indicator GCaMP3 (Tian et al., 2009) in different types of neurons in the OB, we used four Cre-driver mouse lines. Specifically, OMP-Cre (Li et al., 2004), Gad2-Cre (Taniguchi et al., 2011), DATCre (Bäckman et al., 2006), and Pcdh21-Cre (Nagai et al., 2005) mouse lines were crossed with a Cre-inducible GCaMP3 reporter mouse line (Ai38; Zariwala et al., 2012) so that GCaMP3 was expressed in OSNs and GABAergic, dopaminergic, and mitral/tufted cells, respectively. We first verified the GCaMP3 expression pattern in each of the Cre-driver mouse lines (Fig. 1A1-A4). In OMP-Cre mice, GCaMP3 signals were clearly detected only in OSNs in the glomerular layer (GL; Fig. 1A1). Consistent with a previous report (Wachowiak et al., 2013), GCaMP3 in Gad2-Cre mice was strongly expressed in the external plexiform layer (EPL) and in the granule cell layer (GCL); the expression was predominantly by granule cells, but enhanced detection methods also revealed expression by periglomerular cells in the GCL (Fig. 1A2). In DAT-Cre mice, GCaMP3 signals were mostly restricted to the GL (Fig. 1A3). High magnification of this layer indicated that GCaMP3 was expressed by juxtaglomerular cells, which were considered to be short-axon (SA) cells (Kiyokage et al., 2010; Fig. 1A3, inset). This pattern of expression was similar to that in the tyrosine hydroxylase (TH)-Cre line, another driver line for expression in dopaminergic cells (Wachowiak et al., 2013). In Pcdh21-Cre mice, GCaMP3 was specifically expressed in mitral/tufted cells, as GCaMP3 signals appeared in somata and neurite processes in superficial EPL and the mitral cell layer (MCL; Fig. 1A4), as reported previously (Nagai et al., 2005; Mizuguchi et al., 2012; Huang et al., 2013). Although reporter expression is induced in OSNs in another Pcdh21Cre-driver line (Wachowiak et al., 2013), we did not observe this ectopic expression in our mice. In summary, these Cre mouse lines exhibited the expected cell-typespecific GCaMP3 expression patterns.

\section{Identification of homologous glomeruli in medial and lateral maps}

In vivo optical imaging of the dorsal $\mathrm{OB}$ has not been used as a means to record activity in the medial map, because most of the glomeruli are located in the medioventral region of the OB (Johnson et al., 1995, 1999, 2004, 2005, 2009; Johnson and Leon, 1996, 2000; Nagao et al., 2000, 2002; Inaki et al., 2002; Taniguchi et al., 2003; Mori et al., 2006; Zapiec and Mombaerts, 2015). However, it was recently demonstrated that OSNs expressing TAARs project to two or a few glomeruli in caudal regions of the dorsal OB (Johnson et al., 2012; Pacifico et al., 2012; Dewan et al., 2013, 2018; Zhang et al., 2013; Liberles, 2015). These medial and lateral glomeruli can easily be identified, because axons from TAAR-expressing OSNs projecting to the dorsomedial glomeruli transverse the anteromedial (septal) surface of the OB, whereas those projecting to the dorsolateral glomeruli transverse the anterolateral surface. The axonal trajectories and odorant response profiles of glomeruli receiving projections from OSNs expressing TAAR3 and TAAR4 are well 
characterized (Pacifico et al., 2012; Dewan et al., 2013, 2018; Zhang et al., 2013). Specifically, these glomeruli are highly sensitive to IPA and PEA, respectively. Therefore, we imaged simultaneously these medial and lateral glomeruli that receive input from TAAR3-expressing and TAAR4-expressing OSNs.

Using IPA and PEA at final concentrations of $0.02 \%$ and $0.002 \%$, which reliably and specifically induce activation of the glomeruli receiving inputs from TAAR3-expressing and TAAR4-expressing OSNs, respectively (Pacifico et al., 2012; Dewan et al., 2013, 2018; Zhang et al., 2013), we identified distinct pairs of glomeruli comprising OSNs and GABAergic, dopaminergic, and mitral/tufted cells in the caudal areas of the dorsal OB (Figs. 1B, 2A). The locations of these homologous glomeruli are consistent with the positions of glomeruli receiving inputs from TAAR3expressing and TAAR4-expressing neurons in previous reports (Pacifico et al., 2012; Dewan et al., 2013, 2018; Zhang et al., 2013).

To confirm that the glomeruli pairs represent medial and lateral maps, we retrogradely labeled TAAR3-expressing OSN axons by implanting the IPA-responsive glomeruli in OMP-GCaMP3 mice with Dil crystals $(n=3)$. Optical observation performed $8 \mathrm{~h}$ later revealed labeling of OSN axons in both lateral and medial glomeruli (Fig. 1B5). These labeled axons were observed more clearly in fixed tissue $2 \mathrm{~d}$ later (Fig. 1C). Dorsolateral to the lateral IPA-responsive glomerulus, the majority of the labeled axons were oriented in an anterolateral direction (Fig. 1C,D, orange dashed ellipses). By contrast, the majority of axons dorsomedial to the medial IPA-responsive glomerulus were in an anteromedial direction (toward the septum; Fig. 1C,E, yellow dotted ellipses). Notably, multiple glomerular structures were revealed by the terminal branches of labeled axons in the medial region (Fig. $1 F$, red asterisks), indicating that these axons originated from the medial side. Taken together, these results indicate that the pairs of recorded glomeruli were homologous pairs representing both lateral and medial maps. Therefore, our experimental design provides a unique opportunity to record simultaneously the odor-evoked neuronal activity of homologous glomeruli in the medial and lateral maps in OBs.

\section{Similar temporal odor representations between medial and lateral maps in the $\mathrm{OB}$}

The medial and lateral glomeruli pairs represent inputs from odorant receptors of the same type within medial and lateral regions, respectively, of the complex OE structure. Receptors in these regions may be exposed to different air flow rates and mucosal volumes. We hypothesized that these differences would be reflected in the timing of the glomeruli responses. However, the calcium signals from all cell types examined in medial and lateral glomeruli in response to IPA and PEA had similar amplitudes and temporal patterns (Fig. 2B). Further analyses revealed that the timing of odor inputs to both maps was similar, as revealed by the onset latency measured as the time at which the calcium signal exceeded the threshold from first inhalation during odor stimulation (Fig. 3). The rise times of the responses, which are an indicator of response speed and reflect the neuronal spike frequency, were similar between medial and lateral glomeruli (Fig. 4). The rise time was assessed as the duration for the calcium signal to increase from $20 \%$ to $80 \%$ of the peak signal. Conversely, the similar decay times, during which the calcium signal decreased from $100 \%$ to $50 \%$ of the peak signals, suggested that the activity in one glomerulus was not prolonged relative to the other after the odor stimulus was turned off (Fig. 5). Both glomeruli in the pairs had responses that were similar in strength, as indicated by the peak amplitudes (Fig. 6). The results obtained under all experimental conditions are summarized in Table 1. Overall, there were no significant differences between paired glomeruli in onset latency, rise time, decay time, and peak amplitude of the calcium responses in any of the cell types studied (two-tailed paired $t$ tests; Table 2).

\section{Respiration-locked calcium fluctuations in medial maps are larger than in lateral maps}

Oscillatory calcium responses associated with respiration were observed in the optical recordings (Fig. 2B). These respiratory-linked fluctuations in calcium signals in medial glomeruli appeared to be larger in the postsynaptic neurons (i.e., GABAergic, dopaminergic, and mitral/tufted cells in the Gad2-Cre, DAT-Cre, and Pcdh21-Cre lines, respectively) than in the OSNs (i.e., cells in the OMP-Cre line). To examine this quantitatively, we applied a power spectral analysis to the data. Power spectra before and during odor stimulation displayed peak frequencies of 2$4 \mathrm{~Hz}$ (Fig. 7A, arrows), which matches the respiration rhythm under our experimental conditions. These respiration-locked calcium oscillations were detected in all the cell types (Fig. 7B). The peak power spectra at $2-4 \mathrm{~Hz}$ were indeed larger in medial glomeruli than in lateral glomeruli from Gad2-Cre, DAT-Cre, and Pcdh21-Cre mice both before and after odor stimulation but not in OMP-Cre mice. Because the power spectra background levels, which probably correspond to white noise, were higher in the prestimulation period than in the odor stimulation period (Fig. $7 A$ ), we analyzed the data after subtracting the background levels from the power spectra (Extended Data Fig. 7-1; see Materials and Methods); However, this did not alter the conclusions. The statistical analysis is summarized in Figure 7C (two-tailed paired $t$ tests, see Table 2; the datasets are the same as in Figs. 3-6). These differences were observed consistently with $0.02 \%$ and $0.002 \%$ PEA and IPA (two-tailed paired $t$ tests; Table 2). These results suggest that respiration-locked calcium fluctuations in the medial maps are enhanced postsynaptically in the OB. At last, as previous studies reported that the presence of odor stimulation enhances the oscillatory glomerular activity linked to respiration (or sniff; Spors and Grinvald, 2002; Carey et al., 2009), we compared the power between preodor stimulation period and odor stimulation period in the individual glomeruli (Fig. 7D). Consistent to the previous studies, larger respiration-locked modulation was observed during odor stimulation in all cell type, odorants, and concentrations we examined. 
A

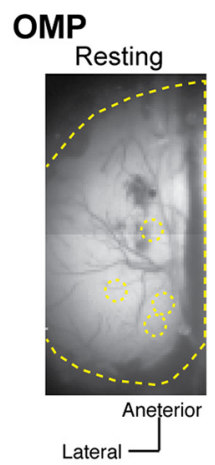

Gad2
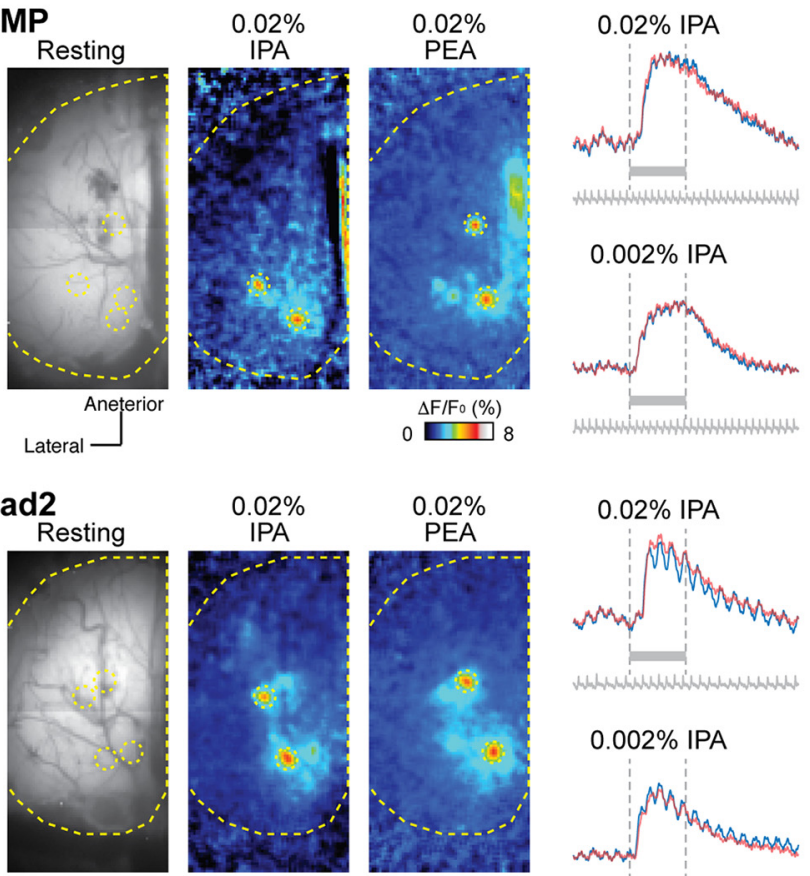

\section{$0.002 \%$ IPA}

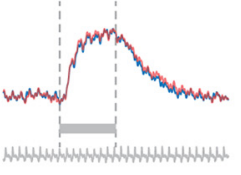

$0.02 \%$ IPA

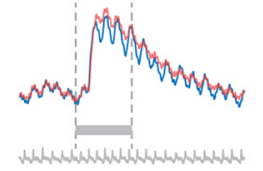

$0.002 \%$ IPA

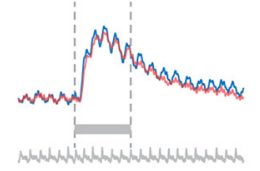

15
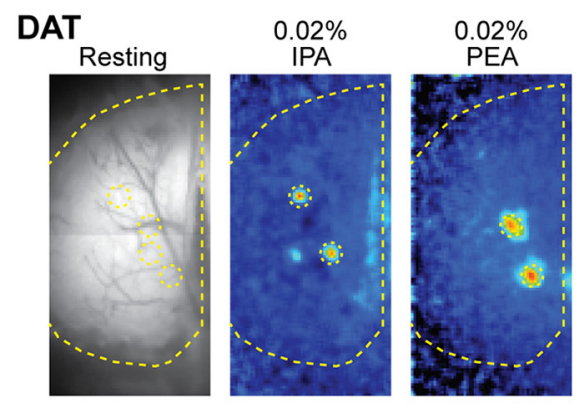

$\Delta \mathrm{F} / \mathrm{F}_{0}(\%)$

$0 \stackrel{\Delta F / F_{0}(\%)}{\square} 15$
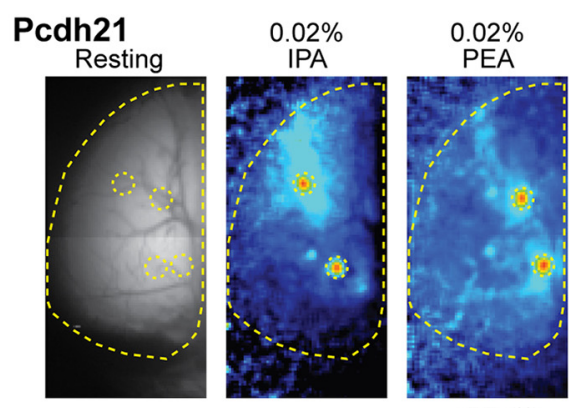

$\Delta \mathrm{F} / \mathrm{F}_{0}(\%)$

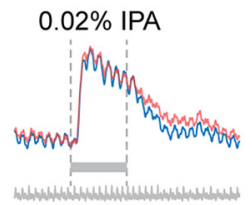

$0.002 \%$ IPA

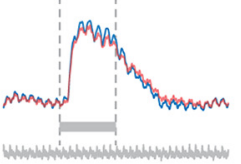

$0.02 \%$ IPA
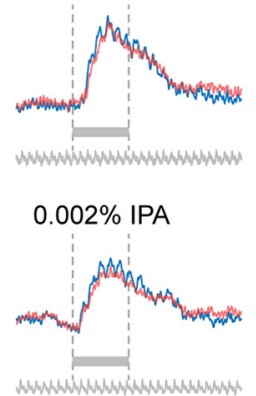

$0.02 \%$ PEA

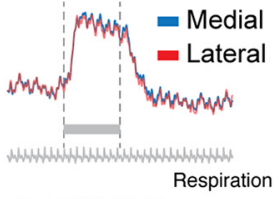

$0.002 \%$ PEA

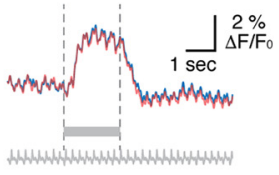

$0.02 \%$ PEA

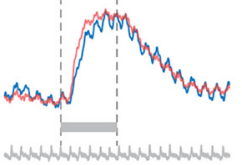

$0.002 \%$ PEA

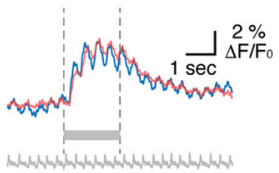

$0.02 \%$ PEA

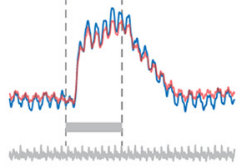

$0.002 \%$ PEA

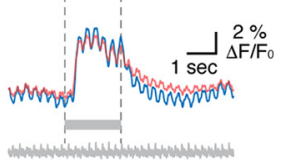

$0.02 \%$ PEA

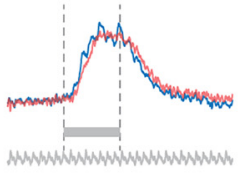

$0.002 \%$ PEA

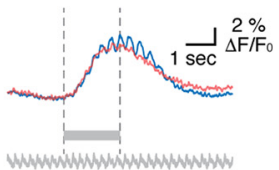

Figure 2. Odor-evoked response maps and traces among different types of OB neurons. Odor-evoked response maps $(\boldsymbol{A})$ and traces $(\boldsymbol{B})$ from OMP-Cre, Gad2-Cre, DAT-Cre, and Pcdh21-Cre mice. Resting GCaMP3 fluorescence images are displayed in the left panels in $\boldsymbol{A}$. Pseudocolored images in the middle and right panels in $\boldsymbol{A}$ indicate responses to $0.02 \%$ IPA and PEA, respectively. Yellow dotted lines and circles in each image show approximately the edge of the left OB and homologous glomeruli evoked by $0.02 \%$ IPA and PEA, respectively. The color scales represent $\Delta F / F_{0}(\%)$ of GCaMP3 signal. Traces shown in B represent GCaMP3 fluorescence changes from two subsets of homologous glomeruli evoked by indicated concentrations of IPA and PEA shown in A. Red and blue traces indicate lateral and medial glomeruli, respectively. Gray bars under each trace and vertical dotted lines indicate the timing of odor stimulation. Respiration signals are also shown under the traces. 
A

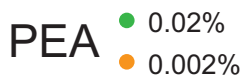

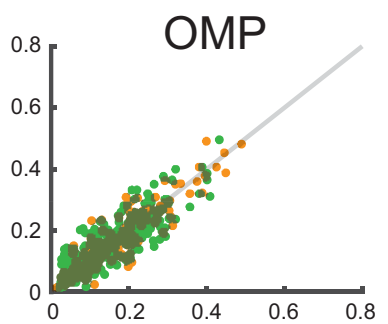

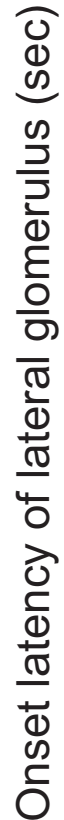

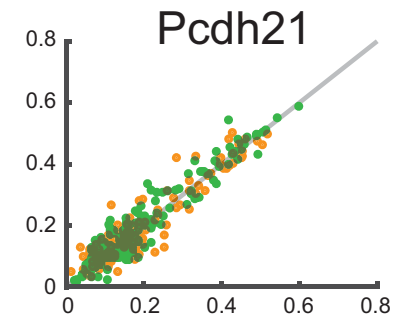

IPA $\bullet 0.02 \%$
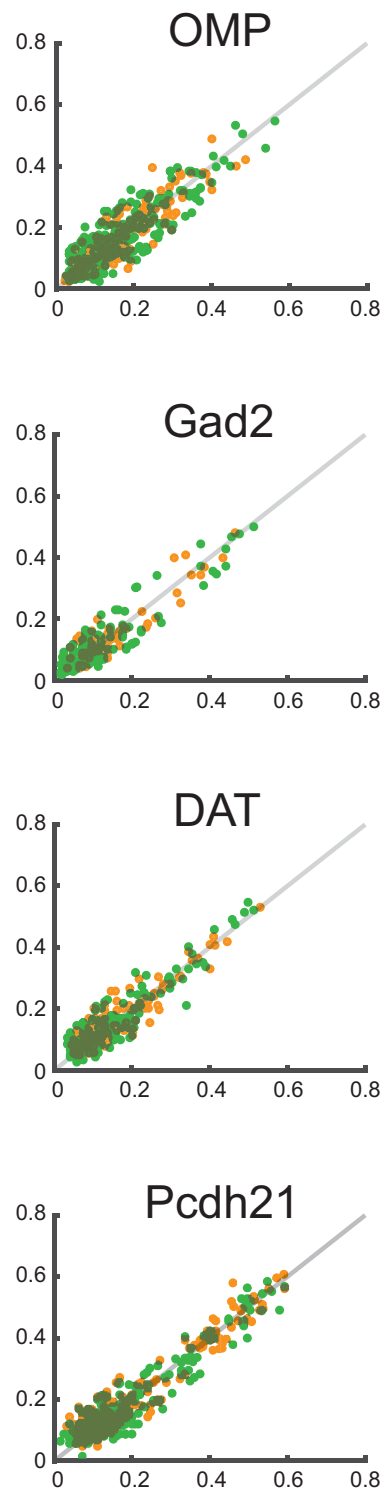

B

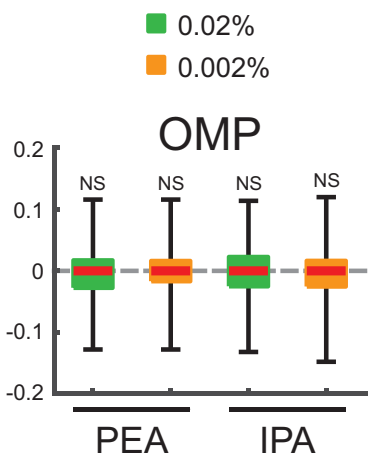

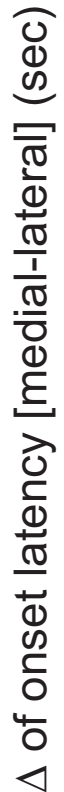
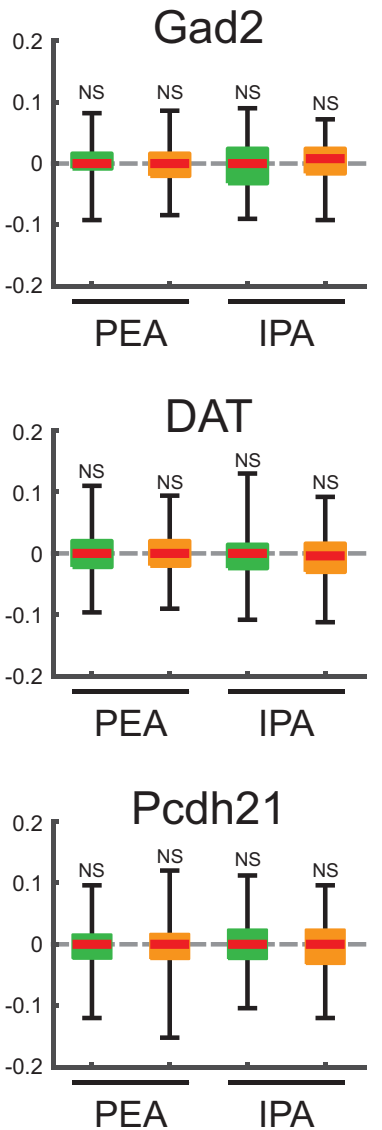

\section{Onset latency of medial glomerulus ( $\mathrm{sec}$ )}

Figure 3. Onset latencies of medial and lateral glomeruli. $\boldsymbol{A}$, Scatter plots displaying the distributions of onset latencies of medial and lateral glomeruli, which responded to PEA and IPA stimuli. $x$ and $y$ axes indicate onset latencies of medial and lateral glomerular responses, respectively. Individual green and orange dots indicate single trial data of $0.02 \%$ and $0.002 \%$ PEA or IPA. Gray lines indicate the equal onset latency time points of medial and lateral glomerular responses. B. Box plots displaying the distributions of the differences of onset latencies between medial and lateral glomeruli responses to $0.02 \%$ and $0.002 \%$ PEA or IPA. Red horizontal lines in each box indicate the medians. Quartiles are shown as whiskers. NS, not significant (two-tailed paired Student's $t$ test).

\section{Discussion}

\section{Odorant response properties of homologous TAAR glomeruli in anesthetized animals}

TAARs are a unique class of olfactory receptor; TAARexpressing neurons project to the posteromedial glomeruli in the dorsal $\mathrm{OB}$ and are sensitive to predator odors
(Liberles and Buck, 2006; Ferrero et al., 2011; Pacifico et al., 2012; Dewan et al., 2013; Zhang et al., 2013; Liberles, 2015). Taking advantage of the unique location of TAAR glomeruli, we compared, for the first time, the odorant response properties of homologous glomeruli in medial and lateral maps. While we did not observe clear differences in response amplitude, rising time, onset latency, or 
A

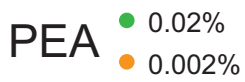
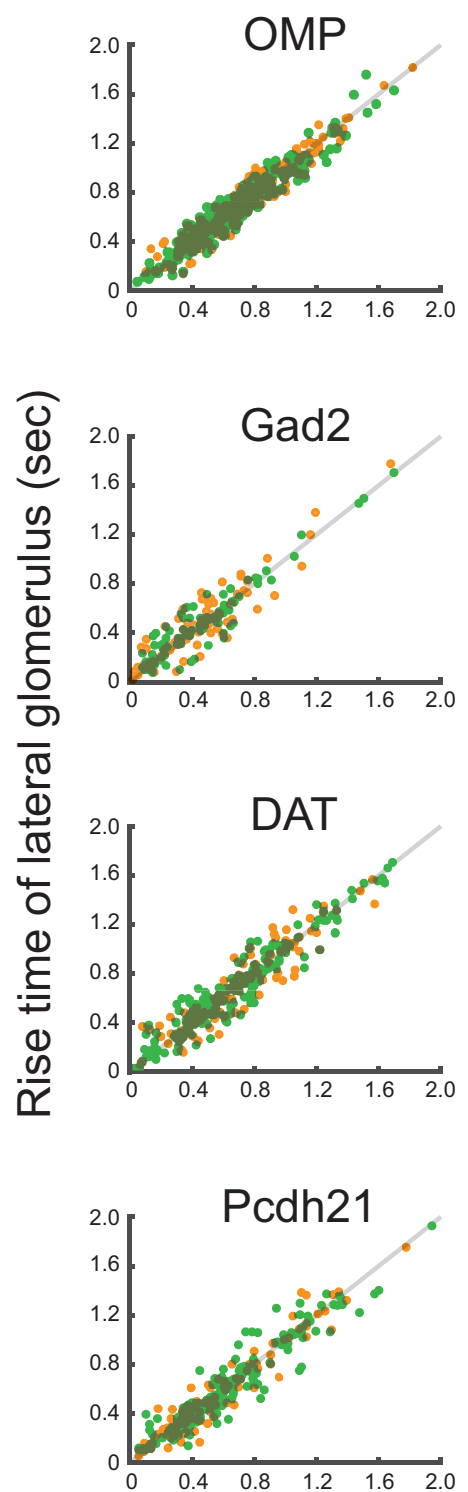

IPA $\bullet 0.02 \%$
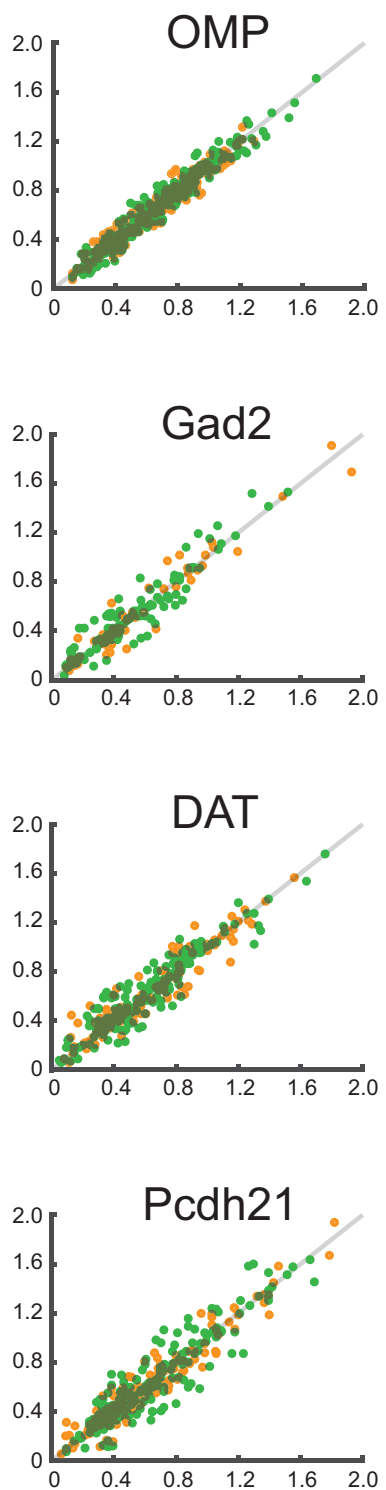

B

$0.02 \%$

$0.002 \%$
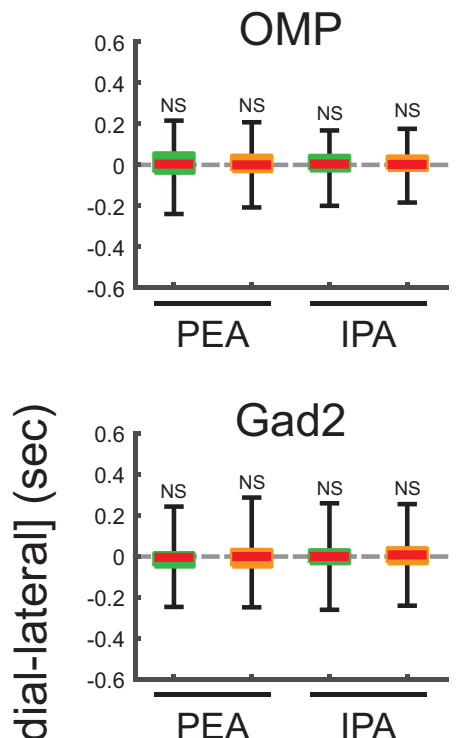

PEA IPA
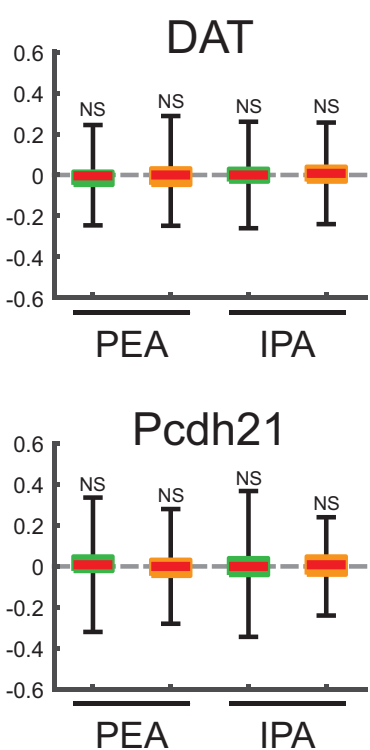

\section{Rise time of medial glomerulus (sec)}

Figure 4. Rise times of medial and lateral glomeruli. A, Scatter plots displaying the distributions of rise times of the medial and lateral glomeruli, which responded to PEA and IPA stimuli. $x$ and $y$ axes indicate rise times of medial and lateral glomerular responses, respectively. Individual green and orange dots indicate single trial data of $0.02 \%$ and $0.002 \%$ PEA or IPA. Gray lines indicate the equal rise time points of medial and lateral glomerular responses. $\boldsymbol{B}$, Box plots displaying the distributions of the differences of rise times between medial and lateral glomerular responses to $0.02 \%$ and $0.002 \%$ PEA or IPA. Red horizontal lines in each box indicate the medians. Quartiles are shown as whiskers. NS, not significant (two-tailed paired Student's $t$ test).

decay time between homologous glomeruli, the medialmap glomeruli showed larger respiration-locked fluctuations than those of lateral-map glomeruli, but only in postsynaptic cell types. One potential caveat in using TAAR glomeruli as a model is that the results may only be pertinent to TAAR glomeruli and may not reflect the properties shared across glomeruli regardless of the class of olfactory receptor. Therefore, it will be necessary to examine odorant response properties in a broader set of glomeruli to generalize the findings of this study.

In addition, it is also important to note that this study was conducted using anesthetized animals. Odor response properties are known to differ between anesthetized and nonanesthetized animals (Kato et al., 2012; Blauvelt et al., 2013; Ogg et al., 2018), probably because strong top-down modulation occurs in awake animals. In 
A

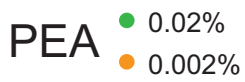
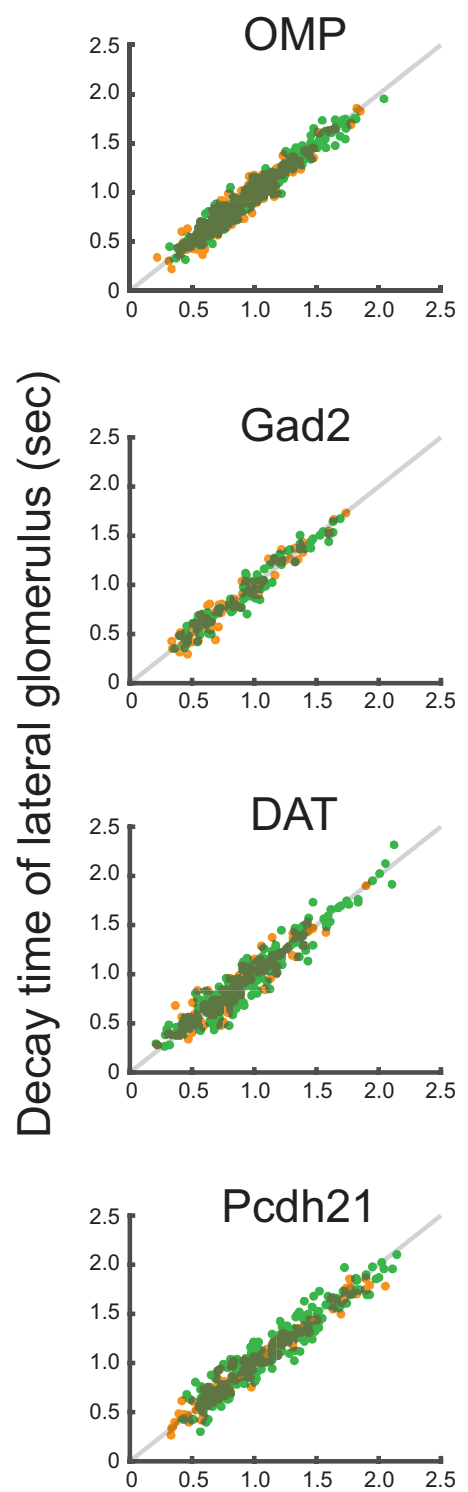

IPA $0.02 \%$
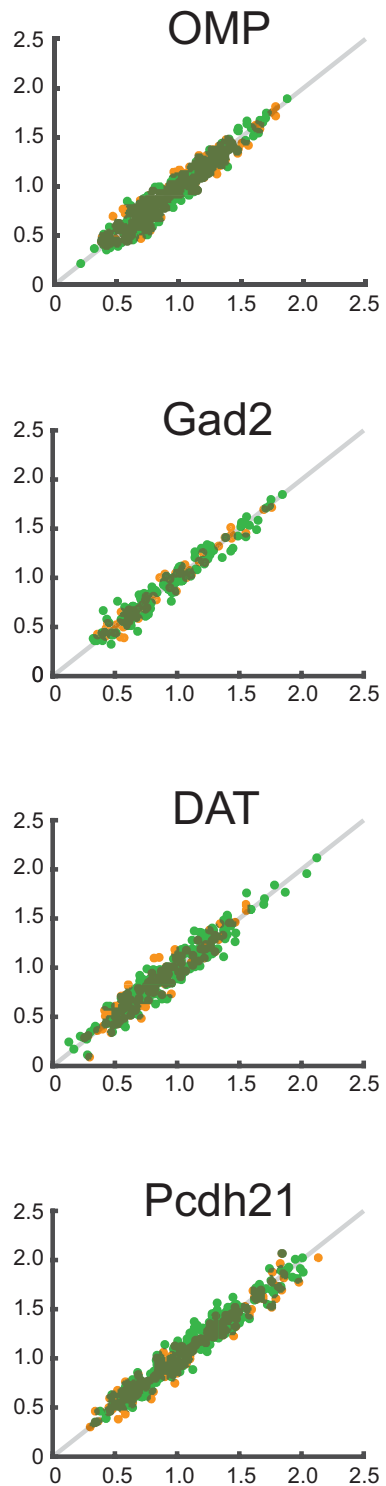

B

$0.02 \%$

$0.002 \%$
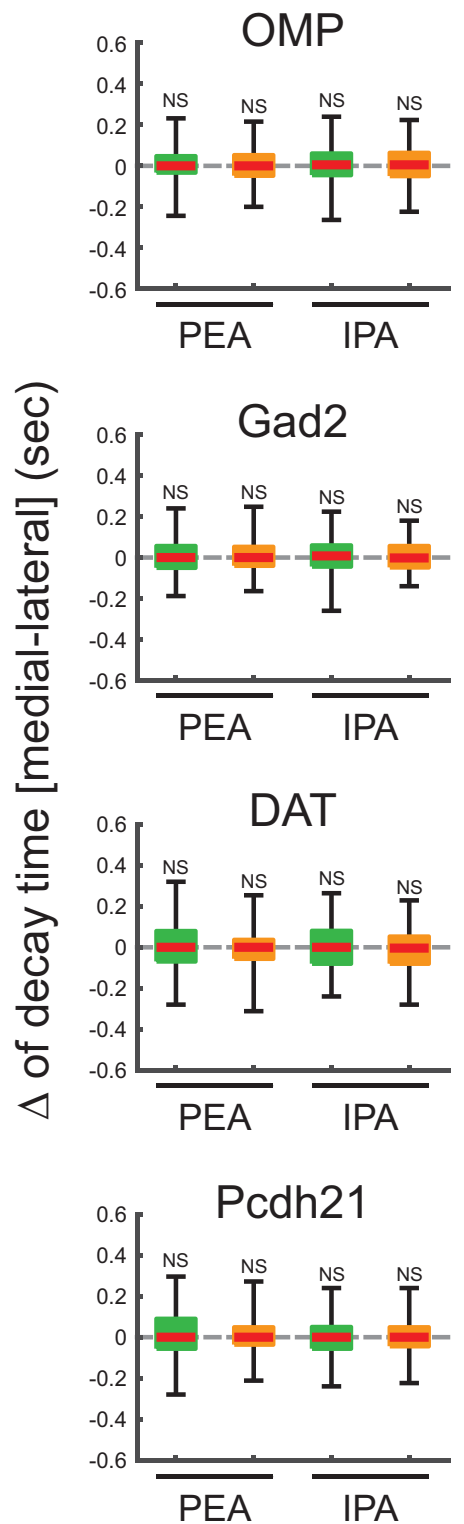

Decay time of medial glomerulus (sec)

Figure 5. Decay times of medial and lateral glomeruli. $\boldsymbol{A}$, Scatter plots displaying the distributions of decay times of the medial and lateral glomeruli, which responded to PEA and IPA stimuli. $x$ and $y$ axes indicate decay times of medial and lateral glomerular responses, respectively. Individual green and orange dots indicate single trial data of $0.02 \%$ and $0.002 \%$ PEA or IPA. Gray lines indicate the equal decay time points of medial and lateral glomerular responses. $\boldsymbol{B}$, Box plots displaying the distributions of the differences of decay times between medial and lateral glomerular responses to $0.02 \%$ and $0.002 \%$ PEA or IPA. Red horizontal lines in each box indicate the medians. Quartiles are shown as whiskers. NS, not significant (two-tailed paired Student's $t$ test).

this study, we used anesthetized animals because the reduced efferent activity in these animals is an advantage in the initial characterization of afferent pathways. Future studies in nonanesthetized animals would help determine whether top-down inputs differentially modulate medial-map and lateral-map glomeruli, which could show that their activities are more diverse than those observed in this study, and would ultimately allow the activities of homologous glomeruli to be correlated with animal behavior.

\section{Presynaptic/postsynaptic calcium events in multiple cell types}

In this work, GCaMP was expressed in postsynaptic GABAergic, dopaminergic, and mitral/tufted cells and in presynaptic axon terminals of OSNs of mice from various 
A

$$
\text { PEA } \stackrel{\bullet 0.02 \%}{\bullet 0.002 \%}
$$
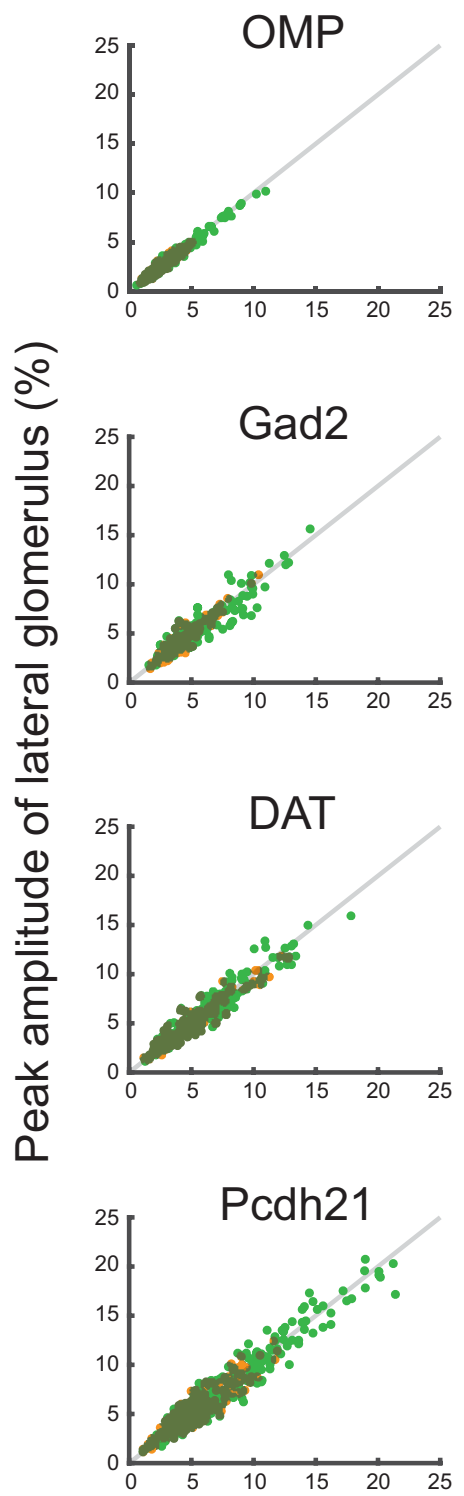

IPA $0.02 \%$
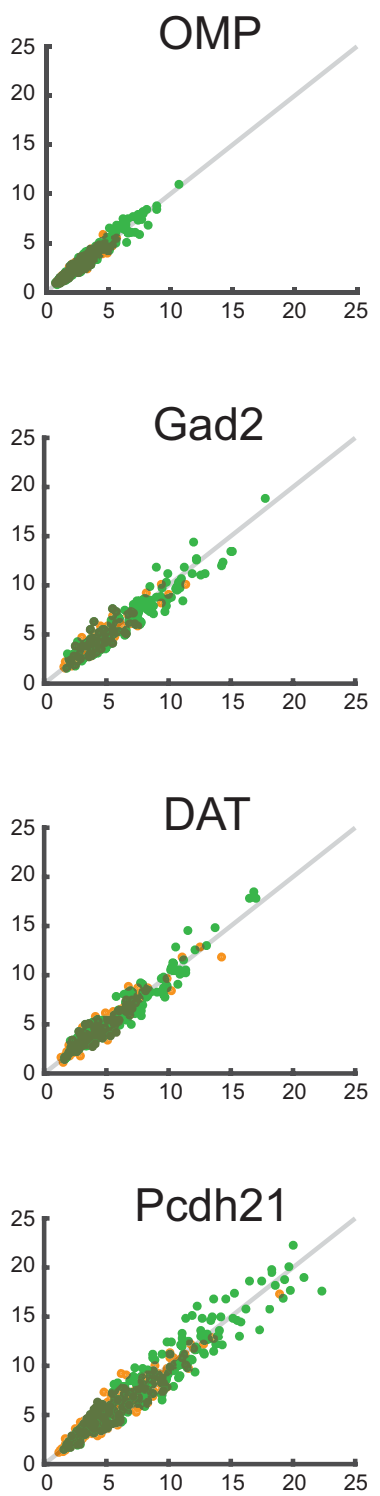

B
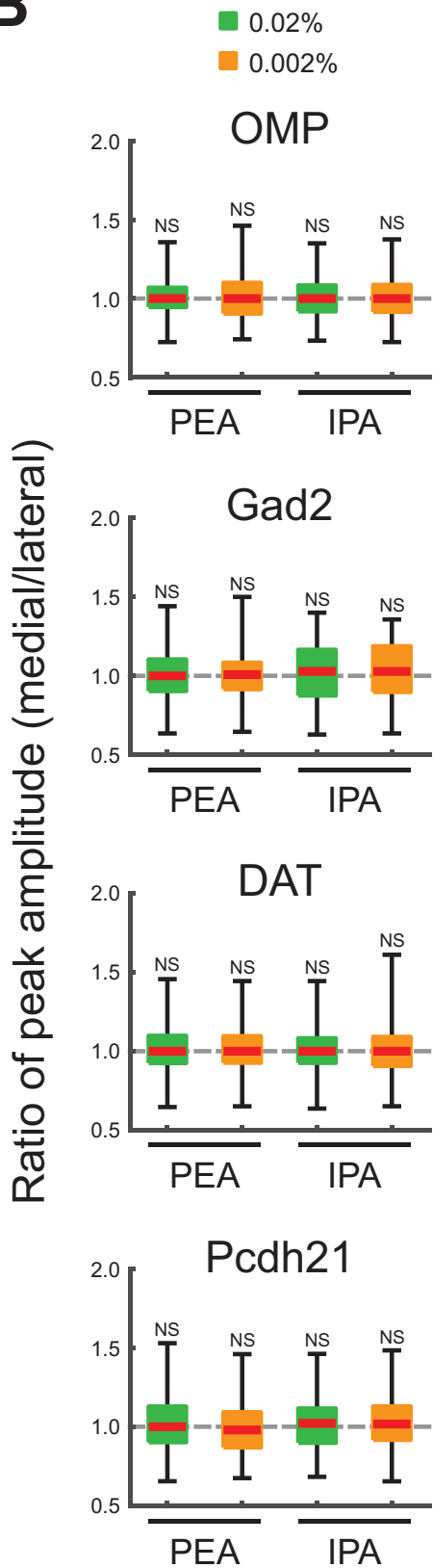

\section{Peak amplitude of medial glomerulus (\%)}

Figure 6. Peak amplitude of medial and lateral glomerular responses. $\boldsymbol{A}$, Scatter plots displaying the distributions of peak amplitudes of medial and lateral glomerular responses to PEA and IPA stimuli. $x$ - and $y$-axes indicate peak amplitudes of medial and lateral glomerular responses, respectively. Individual green and orange dots indicate single trial data of $0.02 \%$ and $0.002 \%$ PEA or IPA. Gray lines indicate the equal peak amplitudes of medial and lateral glomerular responses. B, Box plots displaying the distributions of the differences of peak amplitudes of medial and lateral glomerular responses to $0.02 \%$ and $0.002 \%$ PEA or IPA. Red horizontal lines in each box indicate the medians. Quartiles are shown as whiskers. NS, not significant (two-tailed paired Student's $t$ test).

transgenic Cre-driver lines. Calcium signaling in OSNs reflects activation resulting in transmitter release, whereas calcium signaling in the other cell types may reflect activation of calcium-permeable glutamate receptors and the opening of calcium channels in response to excitatory postsynaptic potentials or spikes initiated in the dendrites or soma (Burnashev et al., 1992; Chen et al., 1997;
Helmchen et al., 1999; Svoboda et al., 1999; Halabisky et al., 2000; Nagayama et al., 2007). Therefore, the calcium influxes in these cells are controlled by different biophysical mechanisms and represent different aspects of biological events. These differences would not impact our imaging results, as the comparisons were between medial and lateral glomeruli comprising the same cell types. 
Table 1: Average and error values in each experimental condition

\begin{tabular}{|c|c|c|c|c|c|c|c|c|}
\hline Figure & Mice & Odorant & Conc, \% & $N$ & $\begin{array}{c}\text { Mean } \\
\text { (medial), s }\end{array}$ & $\begin{array}{c}\mathrm{SD} \\
\text { (medial), s }\end{array}$ & $\begin{array}{c}\text { Mean } \\
\text { (lateral), s }\end{array}$ & $\begin{array}{c}\mathrm{SD} \\
\text { (lateral), s }\end{array}$ \\
\hline $3 A$ & OMP & PEA & 0.02 & 279 & 0.138 & 0.086 & 0.142 & 0.086 \\
\hline $3 A$ & OMP & PEA & 0.002 & 194 & 0.153 & 0.096 & 0.153 & 0.098 \\
\hline $3 A$ & OMP & IPA & 0.02 & 297 & 0.151 & 0.101 & 0.154 & 0.100 \\
\hline $3 A$ & OMP & IPA & 0.002 & 185 & 0.155 & 0.095 & 0.158 & 0.097 \\
\hline $3 A$ & Gad2 & PEA & 0.02 & 106 & 0.103 & 0.099 & 0.108 & 0.096 \\
\hline $3 A$ & Gad2 & PEA & 0.002 & 84 & 0.125 & 0.083 & 0.128 & 0.081 \\
\hline $3 A$ & Gad2 & IPA & 0.02 & 119 & 0.112 & 0.110 & 0.113 & 0.104 \\
\hline $3 A$ & Gad2 & IPA & 0.002 & 62 & 0.143 & 0.105 & 0.146 & 0.101 \\
\hline $3 A$ & DAT & PEA & 0.02 & 216 & 0.157 & 0.132 & 0.158 & 0.127 \\
\hline $3 A$ & DAT & PEA & 0.002 & 118 & 0.162 & 0.128 & 0.162 & 0.125 \\
\hline $3 A$ & DAT & IPA & 0.02 & 184 & 0.148 & 0.096 & 0.152 & 0.098 \\
\hline $3 A$ & DAT & IPA & 0.002 & 123 & 0.160 & 0.098 & 0.166 & 0.093 \\
\hline $3 A$ & Pcdh21 & PEA & 0.02 & 199 & 0.183 & 0.125 & 0.185 & 0.129 \\
\hline $3 A$ & Pcdh21 & PEA & 0.002 & 130 & 0.197 & 0.126 & 0.202 & 0.126 \\
\hline $3 A$ & Pcdh21 & IPA & 0.02 & 241 & 0.179 & 0.128 & 0.178 & 0.123 \\
\hline $3 A$ & Pcdh21 & IPA & 0.002 & 176 & 0.210 & 0.147 & 0.214 & 0.144 \\
\hline $4 A$ & OMP & PEA & 0.02 & 279 & 0.638 & 0.305 & 0.631 & 0.300 \\
\hline $4 A$ & OMP & PEA & 0.002 & 194 & 0.732 & 0.307 & 0.724 & 0.307 \\
\hline $4 A$ & OMP & IPA & 0.02 & 297 & 0.658 & 0.300 & 0.653 & 0.304 \\
\hline $4 A$ & OMP & IPA & 0.002 & 185 & 0.679 & 0.279 & 0.674 & 0.275 \\
\hline $4 A$ & Gad2 & PEA & 0.02 & 106 & 0.425 & 0.302 & 0.441 & 0.300 \\
\hline $4 A$ & Gad2 & PEA & 0.002 & 84 & 0.489 & 0.290 & 0.490 & 0.297 \\
\hline $4 A$ & Gad2 & IPA & 0.02 & 119 & 0.486 & 0.301 & 0.496 & 0.314 \\
\hline $4 A$ & Gad2 & IPA & 0.002 & 62 & 0.549 & 0.377 & 0.543 & 0.381 \\
\hline $4 A$ & DAT & PEA & 0.02 & 216 & 0.651 & 0.357 & 0.656 & 0.352 \\
\hline $4 A$ & DAT & PEA & 0.002 & 118 & 0.656 & 0.324 & 0.654 & 0.328 \\
\hline $4 A$ & DAT & IPA & 0.02 & 184 & 0.594 & 0.310 & 0.606 & 0.308 \\
\hline $4 A$ & DAT & IPA & 0.002 & 123 & 0.597 & 0.311 & 0.602 & 0.301 \\
\hline $4 A$ & Pcdh21 & PEA & 0.02 & 199 & 0.590 & 0.327 & 0.580 & 0.321 \\
\hline $4 A$ & Pcdh21 & PEA & 0.002 & 130 & 0.521 & 0.326 & 0.518 & 0.330 \\
\hline $4 A$ & Pcdh21 & IPA & 0.02 & 241 & 0.590 & 0.313 & 0.585 & 0.327 \\
\hline $4 A$ & Pcdh21 & IPA & 0.002 & 176 & 0.586 & 0.332 & 0.579 & 0.330 \\
\hline $5 A$ & OMP & PEA & 0.02 & 279 & 1.007 & 0.356 & 1.003 & 0.358 \\
\hline $5 A$ & OMP & PEA & 0.002 & 194 & 0.883 & 0.297 & 0.879 & 0.301 \\
\hline $5 A$ & OMP & IPA & 0.02 & 297 & 0.939 & 0.306 & 0.934 & 0.313 \\
\hline $5 A$ & OMP & IPA & 0.002 & 185 & 0.945 & 0.335 & 0.940 & 0.327 \\
\hline $5 A$ & Gad2 & PEA & 0.02 & 106 & 0.890 & 0.340 & 0.888 & 0.337 \\
\hline $5 A$ & Gad2 & PEA & 0.002 & 84 & 0.858 & 0.346 & 0.857 & 0.349 \\
\hline $5 A$ & Gad2 & IPA & 0.02 & 119 & 0.917 & 0.365 & 0.909 & 0.358 \\
\hline $5 A$ & Gad2 & IPA & 0.002 & 62 & 0.846 & 0.349 & 0.845 & 0.352 \\
\hline $5 A$ & DAT & PEA & 0.02 & 216 & 0.936 & 0.386 & 0.930 & 0.388 \\
\hline $5 A$ & DAT & PEA & 0.002 & 118 & 0.850 & 0.316 & 0.853 & 0.311 \\
\hline $5 A$ & DAT & IPA & 0.02 & 184 & 0.926 & 0.356 & 0.928 & 0.361 \\
\hline $5 A$ & DAT & IPA & 0.002 & 123 & 0.839 & 0.295 & 0.849 & 0.301 \\
\hline $5 A$ & Pcdh21 & PEA & 0.02 & 199 & 1.101 & 0.412 & 1.098 & 0.400 \\
\hline $5 A$ & Pcdh21 & PEA & 0.002 & 130 & 0.975 & 0.416 & 0.969 & 0.393 \\
\hline $5 A$ & Pcdh21 & IPA & 0.02 & 241 & 1.083 & 0.399 & 1.088 & 0.396 \\
\hline $5 A$ & Pcdh21 & IPA & 0.002 & 176 & 1.041 & 0.407 & 1.032 & 0.392 \\
\hline $6 A$ & OMP & PEA & 0.02 & 279 & 3.114 & 1.635 & 3.099 & 1.597 \\
\hline $6 A$ & OMP & PEA & 0.002 & 194 & 2.244 & 0.963 & 2.248 & 0.979 \\
\hline $6 A$ & OMP & IPA & 0.02 & 297 & 3.096 & 1.741 & 3.123 & 1.772 \\
\hline $6 A$ & OMP & IPA & 0.002 & 185 & 2.469 & 1.078 & 2.478 & 1.077 \\
\hline $6 A$ & Gad2 & PEA & 0.02 & 106 & 5.910 & 2.435 & 5.869 & 2.360 \\
\hline $6 A$ & Gad2 & PEA & 0.002 & 84 & 4.309 & 1.712 & 4.349 & 1.831 \\
\hline $6 A$ & Gad2 & IPA & 0.02 & 119 & 6.442 & 3.217 & 6.294 & 3.029 \\
\hline $6 A$ & Gad2 & IPA & 0.002 & 62 & 4.695 & 1.982 & 4.626 & 1.950 \\
\hline $6 A$ & DAT & PEA & 0.02 & 216 & 5.895 & 2.866 & 5.870 & 2.763 \\
\hline $6 A$ & DAT & PEA & 0.002 & 118 & 4.739 & 2.480 & 4.693 & 2.312 \\
\hline $6 A$ & DAT & IPA & 0.02 & 184 & 5.851 & 2.892 & 5.877 & 2.991 \\
\hline $6 A$ & DAT & IPA & 0.002 & 123 & 4.266 & 2.174 & 4.290 & 2.142 \\
\hline $6 A$ & Pcdh21 & PEA & 0.02 & 199 & 7.565 & 4.335 & 7.531 & 4.281 \\
\hline $6 A$ & Pcdh21 & PEA & 0.002 & 130 & 5.506 & 2.356 & 5.601 & 2.302 \\
\hline $6 A$ & Pcdh21 & IPA & 0.02 & 241 & 7.610 & 4.344 & 7.576 & 4.301 \\
\hline $6 A$ & Pcdh21 & IPA & 0.002 & 176 & 5.532 & 2.858 & 5.444 & 2.744 \\
\hline
\end{tabular}


Table 2: Summary of statistical analyses

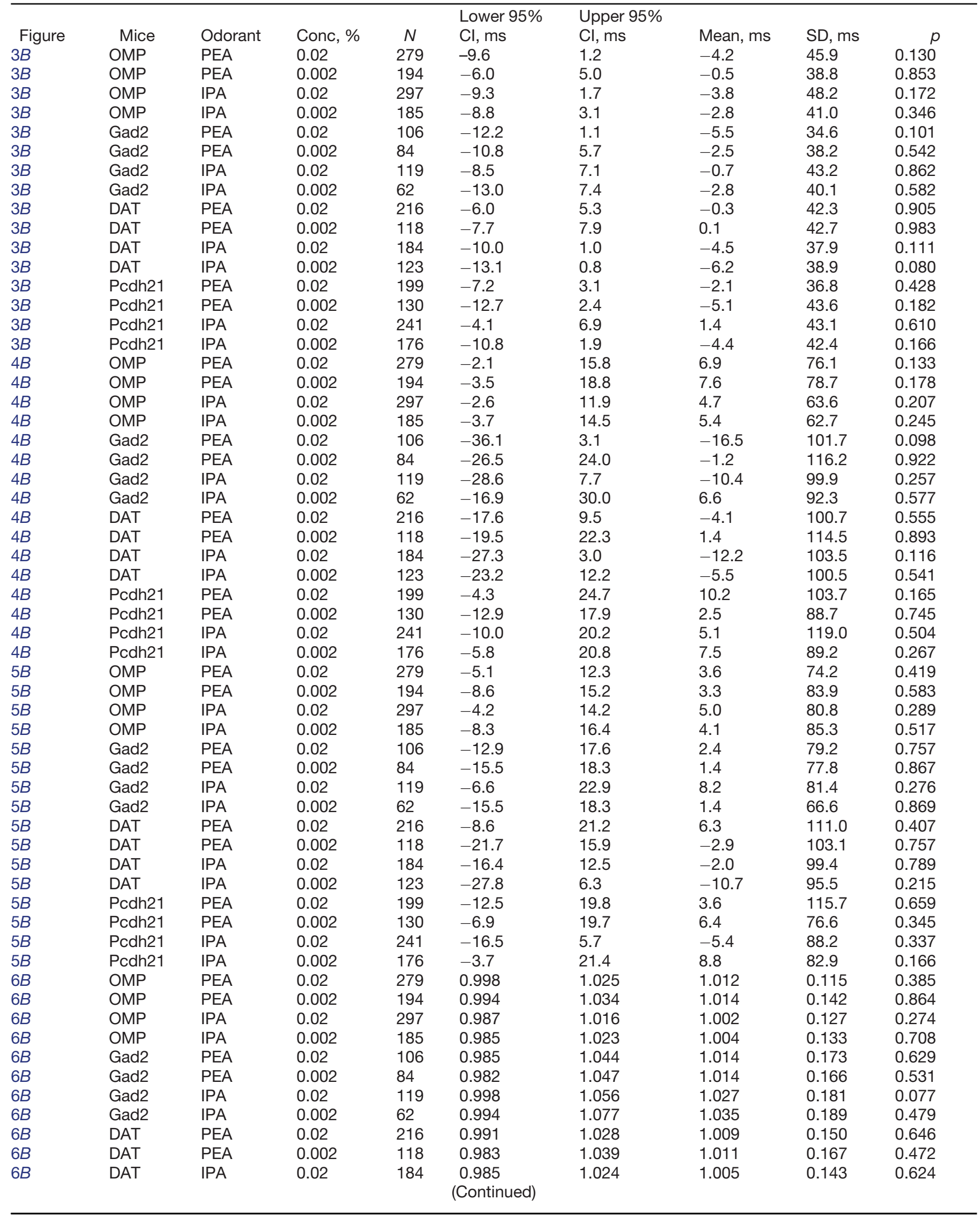


Table 2 Continued

\begin{tabular}{|c|c|c|c|c|c|c|c|c|c|}
\hline Figure & Mice & Odorant & Conc, \% & $N$ & $\begin{array}{l}\text { Lower 95\% } \\
\mathrm{Cl}, \mathrm{ms}\end{array}$ & $\begin{array}{l}\text { Upper 95\% } \\
\text { Cl, ms }\end{array}$ & Mean, ms & $\mathrm{SD}, \mathrm{ms}$ & $p$ \\
\hline $6 B$ & Pcdh21 & PEA & 0.02 & 199 & 0.996 & 1.041 & 1.019 & 0.178 & 0.648 \\
\hline $6 B$ & Pcdh21 & IPA & 0.02 & 241 & 0.997 & 1.037 & 1.017 & 0.170 & 0.652 \\
\hline $6 B$ & Pcdh21 & IPA & 0.002 & 176 & 1.003 & 1.050 & 1.026 & 0.172 & 0.159 \\
\hline 7C Pre & OMP & PEA & 0.02 & 279 & 0.984 & 1.011 & 0.998 & 0.111 & 0.703 \\
\hline 7C Pre & OMP & IPA & 0.002 & 185 & 0.992 & 1.030 & 1.011 & 0.122 & 0.253 \\
\hline 7C Pre & Gad2 & PEA & 0.02 & 106 & 1.300 & 1.407 & 1.354 & 0.289 & $4.011 \mathrm{E}-24$ \\
\hline 7C Pre & Gad2 & PEA & 0.002 & 84 & 1.270 & 1.389 & 1.330 & 0.282 & $1.935 \mathrm{E}-18$ \\
\hline 7C Pre & Gad2 & IPA & 0.02 & 119 & 1.296 & 1.407 & 1.351 & 0.322 & $4.059 E-24$ \\
\hline 7C Pre & Gad2 & IPA & 0.002 & 62 & 1.304 & 1.449 & 1.376 & 0.315 & $4.941 \mathrm{E}-16$ \\
\hline 7C Pre & DAT & PEA & 0.02 & 216 & 1.258 & 1.323 & 1.291 & 0.245 & $3.173 \mathrm{E}-43$ \\
\hline 7C Pre & Pcdh21 & IPA & 0.02 & 241 & 1.292 & 1.357 & 1.325 & 0.273 & $6.790 \mathrm{E}-55$ \\
\hline 7C Pre & Pcdh21 & IPA & 0.002 & 176 & 1.281 & 1.355 & 1.318 & 0.258 & $1.024 \mathrm{E}-39$ \\
\hline 7C Odor & OMP & PEA & 0.02 & 279 & 0.990 & 1.021 & 1.005 & 0.131 & 0.492 \\
\hline 7C Odor & OMP & PEA & 0.002 & 194 & 0.997 & 1.032 & 1.015 & 0.128 & 0.104 \\
\hline 7C Odor & OMP & IPA & 0.02 & 297 & 0.988 & 1.019 & 1.004 & 0.135 & 0.635 \\
\hline 7C Odor & OMP & IPA & 0.002 & 185 & 0.984 & 1.021 & 1.002 & 0.120 & 0.812 \\
\hline 7C Odor & Gad2 & PEA & 0.02 & 106 & 1.475 & 1.630 & 1.552 & 0.415 & $1.008 \mathrm{E}-26$ \\
\hline 7C Odor & Gad2 & PEA & 0.002 & 84 & 1.506 & 1.693 & 1.600 & 0.448 & $1.009 \mathrm{E}-21$ \\
\hline 7C Odor & Gad2 & IPA & 0.02 & 119 & 1.508 & 1.670 & 1.589 & 0.469 & $7.588 \mathrm{E}-29$ \\
\hline 7C Odor & Gad2 & IPA & 0.002 & 62 & 1.491 & 1.652 & 1.571 & 0.350 & $9.631 \mathrm{E}-23$ \\
\hline 7C Odor & DAT & PEA & 0.02 & 216 & 1.405 & 1.495 & 1.450 & 0.338 & $7.929 \mathrm{E}-50$ \\
\hline 7C Odor & DAT & PEA & 0.002 & 118 & 1.424 & 1.564 & 1.494 & 0.382 & $1.060 \mathrm{E}-26$ \\
\hline $7 D$ & OMP & IPA & 0.02 & 594 & 1.371 & 1.434 & 1.403 & 0.388 & $9.829 E-14$ \\
\hline $7 D$ & OMP & IPA & 0.002 & 370 & 1.275 & 1.353 & 1.314 & 0.359 & $3.323 \mathrm{E}-06$ \\
\hline $7 D$ & Gad2 & PEA & 0.02 & 212 & 1.395 & 1.484 & 1.440 & 0.340 & 1.917 E-04 \\
\hline $7 D$ & Gad2 & PEA & 0.002 & 168 & 1.402 & 1.514 & 1.458 & 0.384 & $1.931 \mathrm{E}-04$ \\
\hline $7 D$ & Gad2 & IPA & 0.02 & 238 & 1.404 & 1.496 & 1.450 & 0.379 & $2.091 \mathrm{E}-04$ \\
\hline $7 D$ & Gad2 & IPA & 0.002 & 124 & 1.415 & 1.523 & 1.469 & 0.335 & $1.401 \mathrm{E}-03$ \\
\hline $7 D$ & DAT & PEA & 0.02 & 432 & 1.338 & 1.393 & 1.365 & 0.292 & $8.842 \mathrm{E}-06$ \\
\hline $7 D$ & DAT & PEA & 0.002 & 236 & 1.327 & 1.403 & 1.365 & 0.295 & $4.632 \mathrm{E}-05$ \\
\hline $7 D$ & DAT & IPA & 0.02 & 368 & 1.319 & 1.379 & 1.349 & 0.294 & 8.927 E-05 \\
\hline $7 D$ & DAT & IPA & 0.002 & 246 & 1.307 & 1.387 & 1.347 & 0.309 & $2.816 \mathrm{E}-04$ \\
\hline $7 D$ & Pcdh21 & PEA & 0.02 & 398 & 1.348 & 1.409 & 1.378 & 0.339 & $8.010 \mathrm{E}-03$ \\
\hline $7 D$ & Pcdh21 & PEA & 0.002 & 260 & 1.360 & 1.441 & 1.400 & 0.344 & $5.501 \mathrm{E}-03$ \\
\hline $7 D$ & Pcdh21 & IPA & 0.02 & 482 & 1.363 & 1.416 & 1.390 & 0.314 & $3.800 \mathrm{E}-03$ \\
\hline $7 D$ & Pcdh21 & IPA & 0.002 & 352 & 1.369 & 1.433 & 1.401 & 0.316 & $8.931 \mathrm{E}-04$ \\
\hline
\end{tabular}

Notably, we did not observe cell-type-specific differences between the medial and lateral maps at the glomerular level, which is consistent with recent data at the single-cell level showing the odorant responses of juxtaglomerular cells that are putatively associated with the same glomerulus (Homma et al., 2019). Nevertheless, we cannot exclude the possibility of differential response timing by different cell types, because the time resolution for calcium imaging was limited and did not reflect the activity of all neurons within a glomerulus. Future studies 
A

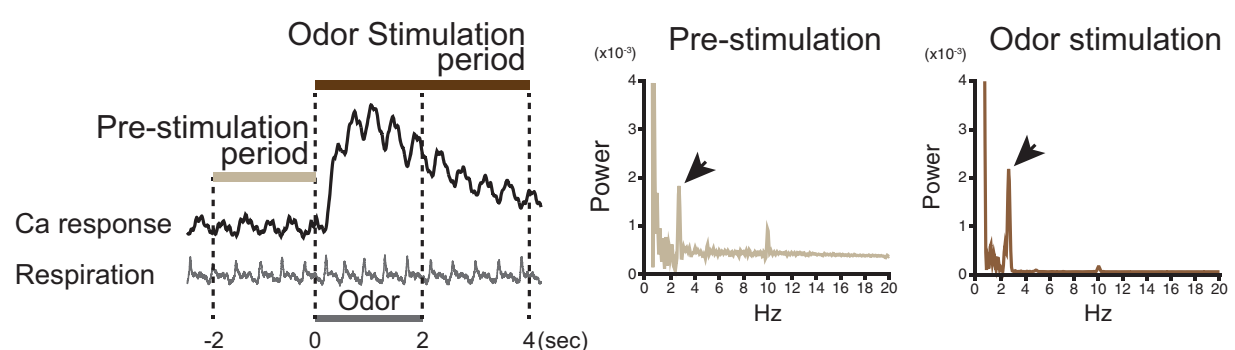

B

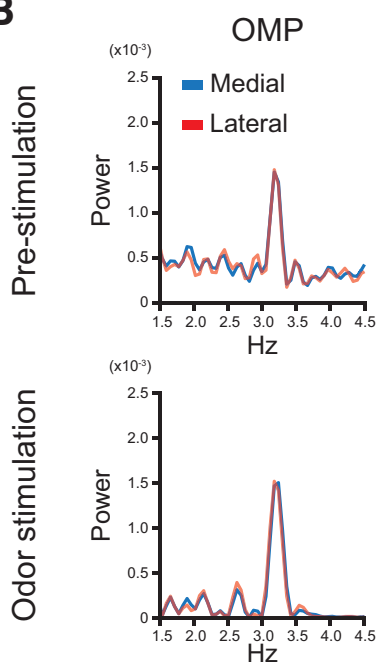

Gad2

DAT

Pcdh21
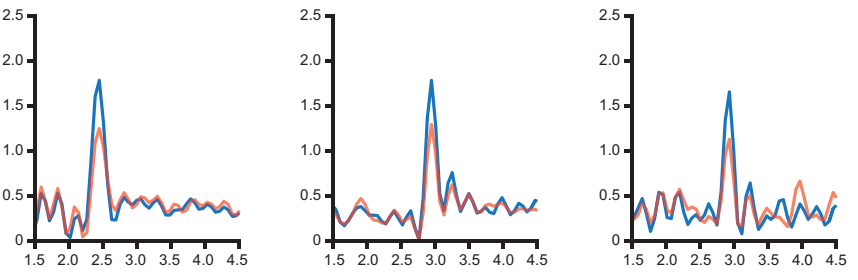

C
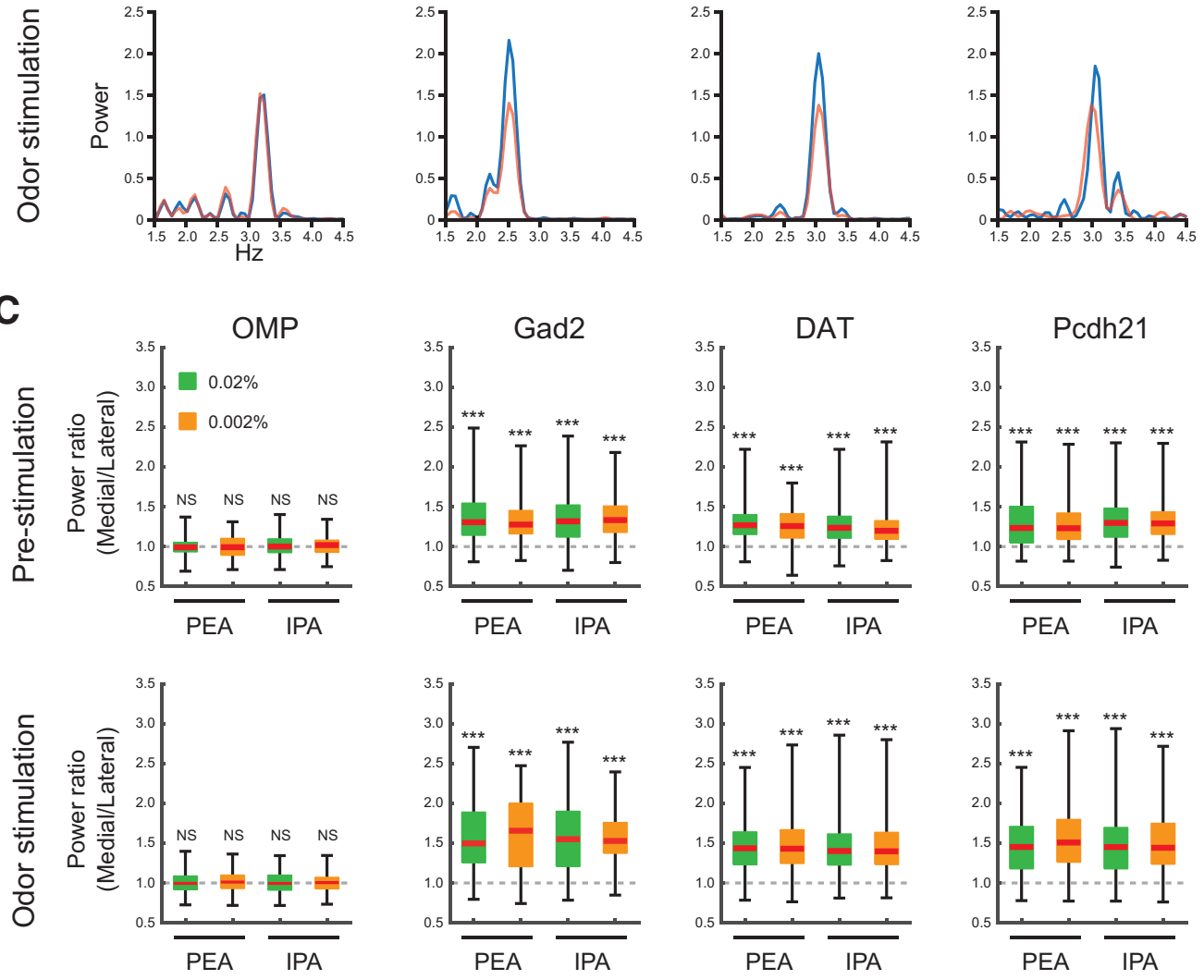

D
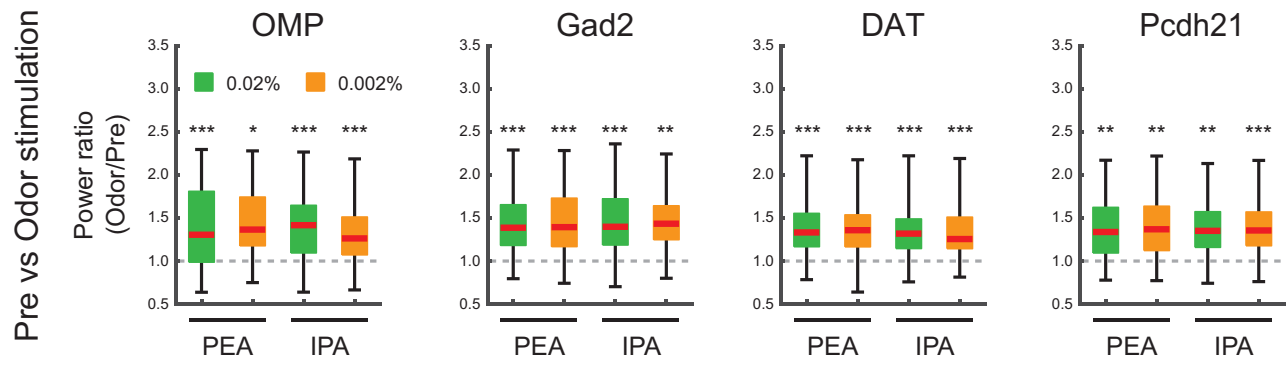
continued

Figure 7. Respiration-locked calcium fluctuations of medial and lateral glomeruli. $\boldsymbol{A}$, Schematic illustration of data collection time points and power spectral analysis. The prestimulation and odor stimulation periods are defined in left panel. Middle and right panels are representative examples of power spectral analyses with large frequency ranges in single trials. Respiration-locked fluctuations of calcium signals were prominently observed at $2-4 \mathrm{~Hz}$ (arrows). $\boldsymbol{B}$, Representative results of power spectral analyses of calcium signals during prestimulation (upper rows) and odor stimulation (lower rows) periods in neurons from GCaMP-expressing OMP-Cre, Gad2Cre, DAT-Cre, and Pcdh21-Cre mice. The calcium response traces of these spectra are shown as $0.02 \%$ IPA response signals in Fig. $2 B$. Blue and red traces indicate medial and lateral glomeruli, respectively (see also Extended Data Fig. 7-1). C, Comparisons of power spectra between the homologous glomeruli during prestimulation (upper rows) and odor stimulation (lower rows) period in neurons from OMP-Cre, Gad2-Cre, DAT-Cre, and Pcdh21-Cre mice. The ratios of peak powers were calculated by dividing the medial glomerular power by the lateral glomerular power in each trial. The powers were calculated after correction for the white-noise background (see Materials and Methods). $\boldsymbol{D}$, Comparisons of peak power between the prestimulation and odor stimulation periods of the same glomeruli in each cell type. The power ratios were calculated by dividing the power value in the odor stimulation period by that in the prestimulation period after the subtraction of background level (see text); $* p<0.05, * * p<0.01, * * * p<0.001$ two-tailed paired Student's $t$ test.

may begin to address this by imaging spike activity at a single-cell resolution.

\section{Response timing of the homologous glomeruli in medial and lateral maps}

A pioneer electrophysiological study using a unique transgenic mouse line in which all OSNs express the same odorant receptor suggested that the latencies of mitral cell responses to odorant stimulation are shorter in the medial map than in the lateral map, especially at a low odorant concentration (Zhou and Belluscio, 2012). Because the $\mathrm{OE}$ is a complicated structure, airflow speed likely varies throughout the nasal cavity, and odorants may reach different areas at different times (Kimbell et al., 1997; Schoenfeld and Cleland, 2006; Zhao et al., 2006). This would produce a time lag for odorant responses in medial and lateral neurons. However, we did not observe different onset latencies between homologous medial and lateral glomeruli, even at low odorant concentrations. This may be because our recordings were via optical imaging rather than electrophysiology and from glomerular rather than MCLs. Another possible reason is the difference in $O B$ regions recorded, which reflect inputs from different OE regions. Our study was restricted to a small region of the posteromedial dorsal $\mathrm{OB}$, which receives inputs from the dorsal OE (Miyamichi et al., 2005). The dorsal OE faces the large nasal cavity and has a relatively simple wall structure compared with that of ventral zones. Moreover, OSNs projecting to medial and lateral maps are close together in the dorsal OE, for which any latency would not be detectable under our experimental conditions. It is possible that differential latencies from neurons in the ventral OB may be larger or more easily detected (Kimbell et al., 1997; Schoenfeld and Cleland, 2006; Zhao et al., 2006). In other words, the time lag may gradually become larger along the dorsal-ventral axis in the OB.

\section{Neuronal/circuitry mechanism of respiration-locked calcium fluctuations}

The fluctuations of calcium responses, which corresponded to the rhythm of respiration, were larger in medial glomeruli than in lateral glomeruli. This may reflect differential airflow volumes or rates along the medial and lateral sides of the nostril. As this was only observed in postsynaptic calcium responses, the modulation is likely not within the OE but in the OB. The mechanism for this modulation may involve the physiological properties of these and/ or associated neurons in medial and lateral glomeruli, such as differences in the expression of various calcium and/or other essential channels. As we did not observe differences in the amplitudes of the calcium responses, more than one channel type may be involved. Differential expression of other essential molecules would also change neuronal and/or network excitability. Neurons in medial glomeruli may also increase and decrease their intracellular calcium levels more synchronously during inhalation and exhalation, respectively. Such synchrony would be expected to affect the overall activity of neurons within a glomerulus; this could more directly be addressed by studies recording neuronal spikes in the context of a circuit. Thus, further investigations are needed to determine the mechanism by which calcium fluctuations are larger in medial glomeruli than in lateral glomeruli in response to odorant stimulation.

\section{Inhibitory connections between the two maps}

Tufted cells in the lateral glomeruli project to cells in the internal plexiform and superficial GCLs underlying the medial glomeruli receiving inputs from the same odorant receptors, and vice versa. These projections activate granule cells and thus inhibit surrounding mitral/tufted cells (Belluscio and Katz, 2001; Lodovichi et al., 2003; Zhou and Belluscio, 2008), resulting in mutual inhibition between the medial and lateral maps. Our data suggest this inhibition is not simple (i.e., one glomerulus is inhibited when the other is activated), as medial and lateral glomeruli are activated simultaneously during odor stimulation. The similar temporal patterns and the absence of counterphase-locked activity between the two glomeruli also suggest that the activity of one glomerulus does not inhibit the other homologous glomerulus in a given time phase, such as during inhalation or exhalation. The functional role of these mutual inhibitory connections and how they contribute to odor processing remain unknown. It is possible that these connections regulate the temporal activity pattern and/or synchrony of neurons or glomeruli in both maps. 


\section{Odor information processing streams from the medial and lateral maps}

One of the unresolved issues is where the medial and lateral maps project and how higher brain centers handle these two outputs. Current knowledge of the connections between the $\mathrm{OB}$ and the olfactory cortex (Nagayama et al., 2010; Ghosh et al., 2011; Miyamichi et al., 2011; Sosulski et al., 2011; Igarashi et al., 2012) suggest that there may not be dramatic differences regarding where the maps project. However, it is still not known whether the outputs from the two maps are evenly transmitted to all olfactory cortical areas, and some regions may preferentially receive input from one or the other. More detailed knowledge of the cortical projections may help reveal the significance of the multiple maps and how the information from the two information streams is compiled in higher brain centers.

\section{Rhythm of respiration}

In vertebrate land animals, airflow through the nasal cavity during respiration alternates between orthonasal and retronasal directions. This induces a synchronized rhythm in the olfactory system, which contributes to the odor information process (Spors and Grinvald, 2002; Wilson and Mainen, 2006; Cury and Uchida, 2010; Uchida et al., 2014). Moreover, the orthonasal and retronasal airflows switch the perception from smells originating from the surrounding environment to taste in the mouth, respectively (Gautam and Verhagen, 2012; Shepherd, 2012). In addition to olfactory areas, respiration-locked oscillations have been observed in hippocampus as well as barrel and prefrontal cortices in the rodent (Shusterman et al., 2011; Phillips et al., 2012; Yanovsky et al., 2014; Lockmann et al., 2016; Nguyen Chi et al., 2016; Biskamp et al., 2017). In the barrel cortex, phaselocked oscillation patterns coordinate the interaction between olfaction and tactile sensations (Ito et al., 2014), whereas freezing behavior is modulated by rhythmic activity in prelimbic prefrontal cortex driven by inputs from the anterior olfactory nucleus (Moberly et al., 2018), which has topographical connections to the OB (Schoenfeld et al., 1985; Yan et al., 2008). The anterior olfactory nucleus sub-region, which dominantly receives inputs from the medial map, may relay this information to higher brain centers controlling respirationlinked neuronal activity associated with mouse behavior. Thus, the anterior olfactory nucleus may be responsible for processing information from multiple glomerular maps and represents an area that warrants further study.

\section{References}

Bäckman CM, Malik N, Zhang Y, Shan L, Grinberg A, Hoffer BJ, Westphal H, Tomac AC (2006) Characterization of a mouse strain expressing Cre recombinase from the $3^{\prime}$ untranslated region of the dopamine transporter locus. Genesis 44:383-390.

Belluscio L, Katz LC (2001) Symmetry, stereotypy, and topography of odorant representations in mouse olfactory bulbs. J Neurosci 21:2113-2122.

Belluscio L, Lodovichi C, Feinstein P, Mombaerts P, Katz LC (2002) Odorant receptors instruct functional circuitry in the mouse olfactory bulb. Nature 419:296-300.
Biskamp J, Bartos M, Sauer JF (2017) Organization of prefrontal network activity by respiration-related oscillations. Sci Rep 7:45508.

Blauvelt DG, Sato TF, Wienisch M, Knöpfel T, Murthy VN (2013) Distinct spatiotemporal activity in principal neurons of the mouse olfactory bulb in anesthetized and awake states. Front Neural Circuits 7:46.

Buck LB (1996) Information coding in the vertebrate olfactory system. Annu Rev Neurosci 19:517-544.

Burnashev N, Khodorova A, Jonas P, Helm PJ, Wisden W, Monyer H, Seeburg PH, Sakmann B (1992) Calcium-permeable AMPA-kainate receptors in fusiform cerebellar glial cells. Science 256:15661570.

Carey RM, Verhagen JV, Wesson DW, Pírez N, Wachowiak M (2009) Temporal structure of receptor neuron input to the olfactory bulb imaged in behaving rats. J Neurophysiol 101:1073-1088.

Chen WR, Midtgaard J, Shepherd GM (1997) Forward and backward propagation of dendritic impulses and their synaptic control in mitral cells. Science 278:463-467.

Cury KM, Uchida N (2010) Robust odor coding via inhalationcoupled transient activity in the mammalian olfactory bulb. Neuron 68:570-585.

Dewan A, Pacifico R, Zhan R, Rinberg D, Bozza T (2013) Non-redundant coding of aversive odours in the main olfactory pathway. Nature 497:486-489.

Dewan A, Cichy A, Zhang J, Miguel K, Feinstein P, Rinberg D, Bozza T (2018) Single olfactory receptors set odor detection thresholds. Nat Commun 9:2887.

Ferrero DM, Lemon JK, Fluegge D, Pashkovski SL, Korzan WJ, Datta SR, Spehr M, Fendt M, Liberles SD (2011) Detection and avoidance of a carnivore odor by prey. Proc Natl Acad Sci USA 108:11235-11240.

Gautam SH, Verhagen JV (2012) Retronasal odor representations in the dorsal olfactory bulb of rats. J Neurosci 32:7949-7959.

Ghosh S, Larson SD, Hefzi H, Marnoy Z, Cutforth T, Dokka K, Baldwin KK (2011) Sensory maps in the olfactory cortex defined by long-range viral tracing of single neurons. Nature 472:217-220.

Halabisky B, Friedman D, Radojicic M, Strowbridge BW (2000) Calcium influx through NMDA receptors directly evokes GABA release in olfactory bulb granule cells. J Neurosci 20:5124-5134.

Helmchen F, Svoboda K, Denk W, Tank DW (1999) In vivo dendritic calcium dynamics in deep-layer cortical pyramidal neurons. Nat Neurosci 2:989-996.

Homma R, Lv X, Sato T, Imamura F, Zeng S, Nagayama S (2019) Narrowly confined and glomerulus-specific onset latencies of odor-evoked calcium transients in the juxtaglomerular cells of the mouse main olfactory bulb. eNeuro 6 .

Huang L, Garcia I, Jen H-I, Arenkiel BR (2013) Reciprocal connectivity between mitral cells and external plexiform layer interneurons in the mouse olfactory bulb. Front Neural Circuits 7:32.

Igarashi KM, leki N, An M, Yamaguchi Y, Nagayama S, Kobayakawa K, Kobayakawa R, Tanifuji M, Sakano H, Chen WR, Mori K (2012) Parallel mitral and tufted cell pathways route distinct odor information to different targets in the olfactory cortex. J Neurosci 32:7970-7985.

Inaki K, Takahashi Y, Nagayama S, Mori K (2002) Molecular-feature domains with posterodorsal-anteroventral polarity in the symmetrical sensory maps of the mouse olfactory bulb: Mapping of odourant-induced Zif268 expression. Eur J Neurosci 15:1563-1574.

Ito J, Roy S, Liu Y, Cao Y, Fletcher M, Lu L, Boughter JD, Grün S, Heck DH (2014) Whisker barrel cortex delta oscillations and gamma power in the awake mouse are linked to respiration. Nat Commun 5:3572.

Johnson BA, Leon M (1996) Spatial distribution of [14C]2-deoxyglucose uptake in the glomerular layer of the rat olfactory bulb following early odor preference learning. J Comp Neurol 376:557-566.

Johnson BA, Leon M (2000) Modular representations of odorants in the glomerular layer of the rat olfactory bulb and the effects of stimulus concentration. J Comp Neurol 422:496-509. 
Johnson BA, Woo CC, Duong H, Nguyen V, Leon M (1995) A learned odor evokes an enhanced Fos-like glomerular response in the olfactory bulb of young rats. Brain Res 699:192-200.

Johnson BA, Woo CC, Hingco EE, Pham KL, Leon M (1999) Multidimensional chemotopic responses to n-aliphatic acid odorants in the rat olfactory bulb. J Comp Neurol 409:529-548.

Johnson BA, Farahbod H, Xu Z, Saber S, Leon M (2004) Local and global chemotopic organization: General features of the glomerular representations of aliphatic odorants differing in carbon number. J Comp Neurol 480:234-249.

Johnson BA, Farahbod H, Leon M (2005) Interactions between odorant functional group and hydrocarbon structure influence activity in glomerular response modules in the rat olfactory bulb. J Comp Neurol 483:205-216.

Johnson BA, Xu Z, Ali SS, Leon M (2009) Spatial representations of odorants in olfactory bulbs of rats and mice: Similarities and differences in chemotopic organization. J Comp Neurol 514:658-673.

Johnson MA, Tsai L, Roy DS, Valenzuela DH, Mosley C, Magklara A, Lomvardas S, Liberles SD, Barnea G (2012) Neurons expressing trace amine-associated receptors project to discrete glomeruli and constitute an olfactory subsystem. Proc Natl Acad Sci USA 109:13410-13415.

Kandel ER, Jessell TM, Schwartz JH, Siegelbaum SA, Hudspeth AJ (2013) Principles of neural science, Ed 5. New York: McGraw-Hill Education.

Kato HK, Chu MW, Isaacson JS, Komiyama T (2012) Dynamic sensory representations in the olfactory bulb: Modulation by wakefulness and experience. Neuron 76:962-975.

Kikuta S, Fletcher ML, Homma R, Yamasoba T, Nagayama S (2013) Odorant response properties of individual neurons in an olfactory glomerular module. Neuron 77:1122-1135.

Kimbell JS, Godo MN, Gross EA, Joyner DR, Richardson RB, Morgan KT (1997) Computer simulation of inspiratory airflow in all regions of the F344 rat nasal passages. Toxicol Appl Pharmacol 145:388-398.

Kiyokage E, Pan Y-Z, Shao Z, Kobayashi K, Szabo G, Yanagawa Y, Obata K, Okano H, Toida K, Puche AC, Shipley MT (2010) Molecular identity of periglomerular and short axon cells. J Neurosci 30:1185-1196.

Li J, Ishii T, Feinstein P, Mombaerts P (2004) Odorant receptor gene choice is reset by nuclear transfer from mouse olfactory sensory neurons. Nature 428:393-399.

Liberles SD (2015) Trace amine-associated receptors: Ligands, neural circuits, and behaviors. Curr Opin Neurobiol 34:1-7.

Liberles SD, Buck LB (2006) A second class of chemosensory receptors in the olfactory epithelium. Nature 442:645-650.

Lockmann AV, Laplagne DA, Leão RN, Tort A (2016) A respirationcoupled rhythm in the rat hippocampus independent of theta and slow oscillations. J Neurosci 36:5338-5352.

Lodovichi C, Belluscio L, Katz LC (2003) Functional topography of connections linking mirror-symmetric maps in the mouse olfactory bulb. Neuron 38:265-276.

Marks CA, Cheng K, Cummings DM, Belluscio L (2006) Activity-dependent plasticity in the olfactory intrabulbar map. J Neurosci 26:11257-11266.

Miyamichi K, Serizawa S, Kimura HM, Sakano H (2005) Continuous and overlapping expression domains of odorant receptor genes in the olfactory epithelium determine the dorsal/ ventral positioning of glomeruli in the olfactory bulb. J Neurosci 25:3586-3592.

Miyamichi K, Amat F, Moussavi F, Wang C, Wickersham I, Wall NR, Taniguchi H, Tasic B, Huang ZJ, He Z, Callaway EM, Horowitz MA, Luo $L$ (2011) Cortical representations of olfactory input by transsynaptic tracing. Nature 472:191-196.

Mizuguchi R, Naritsuka H, Mori K, Yoshihara Y, Klein WH, Yoshihara Y (2012) Tbr2 deficiency in mitral and tufted cells disrupts excitatory-inhibitory balance of neural circuitry in the mouse olfactory bulb. J Neurosci 32:8831-8844.

Moberly AH, Schreck M, Bhattarai JP, Zweifel LS, Luo W, Ma M (2018) Olfactory inputs modulate respiration-related rhythmic activity in the prefrontal cortex and freezing behavior. Nat Commun 9:1528.

Mombaerts P, Wang F, Dulac C, Chao SK, Nemes A, Mendelsohn M, Edmondson J, Axel R (1996) Visualizing an olfactory sensory map. Cell 87:675-686.

Mori K, Takahashi YK, Igarashi KM, Yamaguchi M (2006) Maps of odorant molecular features in the mammalian olfactory bulb. Physiol Rev 86:409-433.

Nagai Y, Sano H, Yokoi M (2005) Transgenic expression of Cre recombinase in mitral/tufted cells of the olfactory bulb. Genesis 43:12-16.

Nagao H, Yoshihara Y, Mitsui S, Fujisawa H, Mori K (2000) Two mirror-image sensory maps with domain organization in the mouse main olfactory bulb. Neuroreport 11:3023-3027.

Nagao H, Yamaguchi M, Takahash Y, Mori K (2002) Grouping and representation of odorant receptors in domains of the olfactory bulb sensory map. Microsc Res Tech 58:168-175.

Nagayama S, Zeng S, Xiong W, Fletcher ML, Masurkar AV, Davis DJ, Pieribone VA, Chen WR (2007) In vivo simultaneous tracing and Ca $(2+)$ imaging of local neuronal circuits. Neuron 53:789-803.

Nagayama S, Enerva A, Fletcher ML, Masurkar AV, Igarashi KM, Mori K, Chen WR (2010) Differential axonal projection of mitral and tufted cells in the mouse main olfactory system. Front Neural Circuits 4:120.

Nguyen Chi V, Müller C, Wolfenstetter T, Yanovsky Y, Draguhn A, Tort ABL, Brankacõk J (2016) Hippocampal respiration-driven rhythm distinct from theta oscillations in awake mice. $\mathrm{J}$ Neurosci 36:162-177.

Ogg MC, Ross JM, Bendahmane M, Fletcher ML (2018) Olfactory bulb acetylcholine release dishabituates odor responses and reinstates odor investigation. Nat Commun 9:1868.

Pacifico R, Dewan A, Cawley D, Guo C, Bozza T (2012) An olfactory subsystem that mediates high-sensitivity detection of volatile amines. Cell Rep 2:76-88.

Phillips ME, Sachdev RNS, Willhite DC, Shepherd GM (2012) Respiration drives network activity and modulates synaptic and circuit processing of lateral inhibition in the olfactory bulb. $J$ Neurosci 32:85-98.

Schindelin J, Arganda-Carreras I, Frise E, Kaynig V, Longair M, Pietzsch T, Preibisch S, Rueden C, Saalfeld S, Schmid B, Tinevez J-Y, White DJ, Hartenstein V, Eliceiri K, Tomancak P, Cardona A (2012) Fiji: An open-source platform for biological-image analysis. Nat Methods 9:676-682.

Schoenfeld TA, Cleland TA (2006) Anatomical contributions to odorant sampling and representation in rodents: Zoning in on sniffing behavior. Chem Senses 31:131-144.

Schoenfeld TA, Marchand JE, Macrides F (1985) Topographic organization of tufted cell axonal projections in the hamster main olfactory bulb: An intrabulbar associational system. J Comp Neurol 235:503-518.

Shepherd GM (2012) Neurogastronomy: How the brain creates flavor and why it matters. New York: Columbia University Press.

Shusterman R, Smear MC, Koulakov AA, Rinberg D (2011) Precise olfactory responses tile the sniff cycle. Nat Neurosci 14:10391044.

Sosulski DL, Bloom ML, Cutforth T, Axel R, Datta SR (2011) Distinct representations of olfactory information in different cortical centres. Nature 472:213-216.

Spors H, Grinvald A (2002) Spatio-temporal dynamics of odor representations in the mammalian olfactory bulb. Neuron 34:301315.

Svoboda K, Helmchen F, Denk W, Tank DW (1999) Spread of dendritic excitation in layer $2 / 3$ pyramidal neurons in rat barrel cortex in vivo. Nat Neurosci 2:65-73.

Taniguchi H, He M, Wu P, Kim S, Paik R, Sugino K, Kvitsiani D, Kvitsani D, Fu Y, Lu J, Lin Y, Miyoshi G, Shima Y, Fishell G, Nelson SB, Huang ZJ (2011) A resource of Cre driver lines for genetic targeting of GABAergic neurons in cerebral cortex. Neuron 71:9951013. 
Taniguchi M, Nagao H, Takahashi YK, Yamaguchi M, Mitsui S, Yagi T, Mori K, Shimizu T (2003) Distorted odor maps in the olfactory bulb of semaphorin 3A-deficient mice. J Neurosci 23:1390-1397.

Tian L, Hires SA, Mao T, Huber D, Chiappe ME, Chalasani SH, Petreanu L, Akerboom J, McKinney SA, Schreiter ER, Bargmann Cl, Jayaraman V, Svoboda K, Looger LL (2009) Imaging neural activity in worms, flies and mice with improved GCaMP calcium indicators. Nat Methods 6:875-881.

Uchida N, Poo C, Haddad R (2014) Coding and transformations in the olfactory system. Annu Rev Neurosci 37:363-385.

Wachowiak M, Economo MN, Díaz-Quesada M, Brunert D, Wesson DW, White JA, Rothermel M (2013) Optical dissection of odor information processing in vivo using GCaMPs expressed in specified cell types of the olfactory bulb. J Neurosci 33:5285-5300.

Wilson RI, Mainen ZF (2006) Early events in olfactory processing. Annu Rev Neurosci 29:163-201.

Yan Z, Tan J, Qin C, Lu Y, Ding C, Luo M (2008) Precise circuitry links bilaterally symmetric olfactory maps. Neuron 58:613-624.

Yanovsky Y, Ciatipis M, Draguhn A, Tort ABL, Brankacõk J (2014) Slow oscillations in the mouse hippocampus entrained by nasal respiration. J Neurosci 34:5949-5964.
Zapiec B, Mombaerts P (2015) Multiplex assessment of the positions of odorant receptor-specific glomeruli in the mouse olfactory bulb by serial two-photon tomography. Proc Natl Acad Sci USA 112: E5873-E5882.

Zariwala HA, Borghuis BG, Hoogland TM, Madisen L, Tian L, De Zeeuw Cl, Zeng H, Looger LL, Svoboda K, Chen T-W (2012) A Cre-dependent GCaMP3 reporter mouse for neuronal imaging in vivo. J Neurosci 32:3131-3141.

Zhang J, Pacifico R, Cawley D, Feinstein P, Bozza T (2013) Ultrasensitive detection of amines by a trace amine-associated receptor. J Neurosci 33:3228-3239.

Zhao K, Dalton P, Yang GC, Scherer PW (2006) Numerical modeling of turbulent and laminar airflow and odorant transport during sniffing in the human and rat nose. Chem Senses 31:107-118.

Zhou Z, Belluscio L (2008) Intrabulbar projecting external tufted cells mediate a timing-based mechanism that dynamically gates olfactory bulb output. J Neurosci 28:9920-9928.

Zhou Z, Belluscio L (2012) Coding odorant concentration through activation timing between the medial and lateral olfactory bulb. Cell Rep 2:1143-1150. 